Portland State University

PDXScholar

Summer 1-1-2012

\title{
Social Job Characteristics and Older Workers: \\ Effects on Job Satisfaction and Job Tension
}

Jennifer Rae Rineer

Portland State University

Follow this and additional works at: https://pdxscholar.library.pdx.edu/open_access_etds

Part of the Industrial and Organizational Psychology Commons, Personality and Social Contexts Commons, and the Social Psychology Commons

Let us know how access to this document benefits you.

\section{Recommended Citation}

Rineer, Jennifer Rae, "Social Job Characteristics and Older Workers: Effects on Job Satisfaction and Job Tension" (2012). Dissertations and Theses. Paper 613.

https://doi.org/10.15760/etd.613

This Thesis is brought to you for free and open access. It has been accepted for inclusion in Dissertations and Theses by an authorized administrator of PDXScholar. Please contact us if we can make this document more accessible: pdxscholar@pdx.edu. 
Social Job Characteristics and Older Workers: Effects on Job Satisfaction and Job

Tension

by

Jennifer Rae Rineer

A thesis submitted in partial fulfillment of the

requirements for the degree of

Master of Science

in

Psychology

Thesis Committee:

Donald Truxillo, Chair

Todd Bodner

Leslie Hammer

Portland State University

2012 


\begin{abstract}
The workforce in most industrialized countries is aging and becoming more age diverse, but few studies have examined the implications of age differences in the design of jobs. This study examined the role of age as a moderator in the relationship between job characteristics and two individual outcomes, job satisfaction and job tension. Specifically, the study focused on the relationship between social characteristics of the job (given social support, [received] social support, interdependence, interaction outside the organization, and feedback from others) and job tension and job satisfaction among Portland Water Bureau employees. Based in Socioemotional Selectivity (SES) theory (Carstensen, 1991), I hypothesized that these job characteristics would have a differential relationship with these outcomes for older and younger workers. Results showed that four of the eight hypothesized interactions were significant, providing support for age as a moderating variable. Differential interaction effects were demonstrated on job satisfaction and job tension. Further, this study incorporated a new conceptualization and measurement of the social support job characteristic (given social support), which demonstrated utility in predicting outcomes. Subjective age was also found to moderate the relationship between job satisfaction and job attitudes, but in a pattern similar to that found for chronological age. This study contributes to the existing literature by answering the call to examine the role of individual differences in the relationship between job design features and outcomes, and by increasing knowledge of the types of job characteristics that increase job satisfaction and reduce job tension for older and younger
\end{abstract}


employees. Implications for the aging workforce are discussed along with future research to better understand the mediating mechanisms. 


\section{Table of Contents}

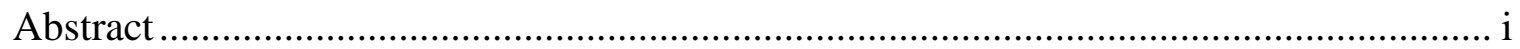

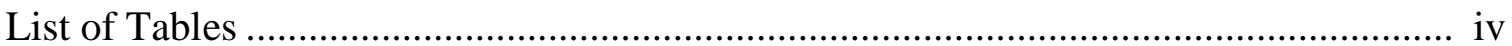

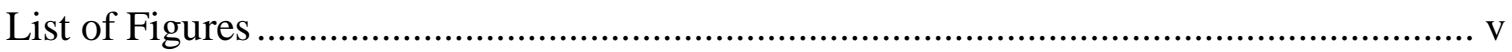

Chapter 1

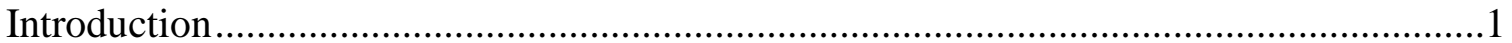

Chapter 2

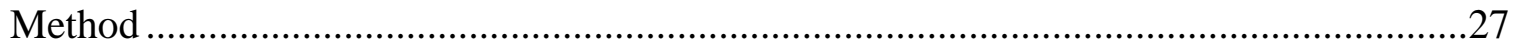

Chapter 3

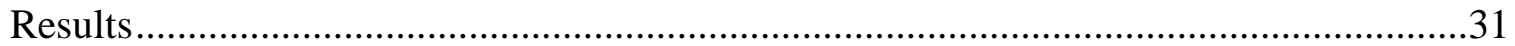

Chapter 4

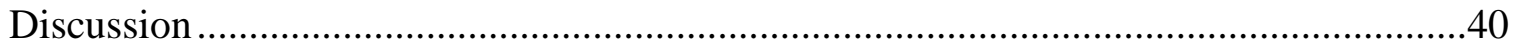

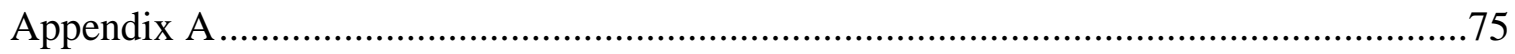

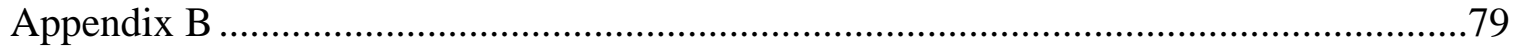

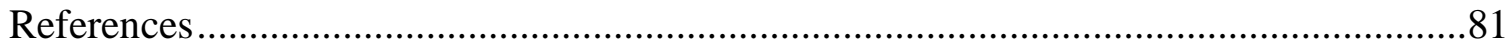




\section{List of Tables}

Table 1

Means, Standard Deviations, and Intercorrelations among Study Variables

Table 2

Summary of Interaction Hypothesis Results of Effects of Social Job Characteristics and Age on

Job Satisfaction and Job Tension

Table 3

Hierarchical Multiple Regression Analyses Predicting Job Satisfaction and Job Tension from

Given Social Support and Age (Chronological and Subjective).

Table 4

Hierarchical Multiple Regression Analyses Predicting Job Satisfaction and Job Tension from

Social Support and Age (Chronological and Subjective)....

\section{Table 5}

Hierarchical Multiple Regression Analyses Predicting Job Satisfaction and Job Tension from Interdependence and Age (Chronological and Subjective)

Table 6

Hierarchical Multiple Regression Analyses Predicting Job Satisfaction and Job Tension from Interaction Outside the Organization and Age (Chronological and Subjective).

\section{Table 7}

Hierarchical Multiple Regression Analyses Predicting Job Satisfaction and Job Tension from Feedback from Others and Age (Chronological and Subjective). 


\section{List of Figures}

Figure 1

Model of study variables

Figure 2

Interaction of given social support and chronological age on job satisfaction

Figure 3

Interaction of given social support and chronological age on job tension.

Figure 4

Interaction of social support and chronological age on job tension..............................68

Figure 5

Interaction of feedback from others and chronological age on job satisfaction

Figure 6

Interaction of given social support and comparative age on job tension

Figure 7

Interaction of social support and comparative age on job tension

Figure 8

Interaction between interaction outside the organization and comparative age on job

satisfaction

Figure 9

Interaction between feedback from others and comparative age on job satisfaction.

Figure 10

Proposed model for future research 


\section{Chapter 1 \\ Introduction}

The age demographics of the world's workforce are changing rapidly. It is

estimated that by 2018, approximately one quarter of the U.S. workforce will be age 55 or older (Tossi, 2009). It is also projected that by 2050, the population of older workers (age 55-64) in Europe will increase by up to 60\% (Carone \& Costello, 2006).

Additionally, because life expectancies and quality of life in mid-to-late adulthood are increasing, employees can now work later in life than they once did. Furthermore, in response to the recent worsening of economic conditions, people may need to work longer to supplement their retirement income, and many countries in Europe and North America are increasing the retirement age.

Because of these economic and demographic shifts, the workplace is becoming increasingly more age-diverse. As a result, there is increased research interest in how age relates to issues such as motivation (e.g., Kanfer \& Ackerman, 2004), job performance (Ng \& Feldman, 2008), and job attitudes (Ng \& Feldman, 2010). Moreover, there is interest in understanding and supporting employees at all phases of the lifespan, so as to improve organizational effectiveness and employee well-being. However, there has been relatively little empirical work on how to design jobs for people at different life stages so that they can continue to work successfully. This study will begin to address this gap by investigating how age moderates the relationship between job design characteristics, specifically, social aspects of the job, and employee outcomes, as outlined by Socioemotional Selectivity Theory (SES; Carstensen, 1991). I will use job tension and 
job satisfaction as my outcome measures of interest, because of their significant impact on both individual and organizational health. The correlates of job tension and job satisfaction (e.g., life satisfaction, turnover intentions, and performance) are outlined below.

\section{Context, Concepts, and Theory}

\section{Job Tension and Job Satisfaction}

Job tension, which is mental and/or physical strain caused by work-related stressors (Sauter et al., 1999), has been shown to affect a variety of individual and organizational outcomes. High levels of job tension have been shown to impact turnover intentions, value attainment, job satisfaction (Zivnuska, Kiewitz, Hochwater, Perrewe, \& Zellars, 2002), absenteeism, and performance (Dwyer \& Ganster, 1991). Job tension has also been shown to cause family disruption, which in turn feeds back into work behaviors (Jackson, 1982). Further, job tension has been identified as a major and rising concern that has increased dramatically in recent decades (LeBlanc, de Jonge, \& Schaufeli, 2000).

Job satisfaction, defined as a cognitive and/or affective evaluation of one's job as more or less positive or negative (Brief \& Weiss, 2002), is an important variable in organizational research, as it has also been linked to numerous individual and organizational outcomes. Job satisfaction has been shown to lead to increased job performance (both in-role and extra-role) (Riketta, 2008). It has also been identified as a mechanism through which organizational citizenship behaviors (OCBs) are enhanced (Organ \& Ryan, 1995). In addition, job satisfaction has been shown to affect satisfaction in other life domains, such as satisfaction with family life (Ford, Heinen, \& Langkamer, 
2007). When considering the experience of older workers, it is also important to note that job satisfaction has been shown to relate to turnover intentions (transfer intentions) and retirement (retirement intentions). When workers are not satisfied with their jobs, they tend to become withdrawn from their jobs and become more likely to consider leaving the organization (Adams \& Beehr, 1998).

Because of the serious effects of job tension and job satisfaction on both individuals and organizations, it is important to understand the antecedents to these attitudes and experiences. The present study will investigate which job characteristics are related to increased job satisfaction and decreased job tension among older versus younger workers. The goal of this study is to produce information that organizations can use to help them optimize the work experience for employees throughout the lifespan.

\section{Job Design Models}

Currently, job design is defined as:

The study, creation, and modification of the composition, content, structure, and environment within which jobs and roles are enacted. As such, it concerns who is doing the work, what is done at work, the interrelationship of different work elements, and the interplay of job and role enactment with the broader task, social, physical, and organizational context. (Morgeson \& Humphrey, 2008, p. 47)

While this more recent definition is broad and incorporates many aspects of the work environment, earlier conceptualizations of job design were much narrower and focused on relatively limited aspects of the job. The following provides a brief overview of the 
history and various schools of job design theory (for a more comprehensive review, see Grant, Fried, \& Juillerat, 2010).

One of the first theories of job design in the United States was Frederick Taylor's "scientific management" approach. In his book, The Principles of Scientific Management (1911), Taylor advocated for the "de-skilling" of work. The goal of scientific management was to mechanize work to improve efficiency. Taylor suggested that tasks be carefully simplified, compartmentalized, and standardized, so that the influence of the workers themselves would be reduced. In the 1920's, however, research conducted at the Western Electric Company at Hawthorne Plant, revealed the importance of human relations in the workplace (Barling \& Griffiths, 2011). These studies originally sought to use a Tayloristic framework to investigate the relationships between various working conditions and productivity. However, the researchers learned that simply paying attention to the employees and showing concern for their working conditions increased productivity (regardless of the actual changes that were made). Thus, job design moved from a mechanism used to make work more automatic and robotic to an approach that considered the role of the individual.

Research in Europe also began to show the downside of the scientific management approach. In 1951, Trist and Bamforth showed that when coal miners' work changed from a whole-task, skilled, autonomous system to a mechanized, fractured system with isolated workers, miners experienced higher levels of anxiety, depression, and anger. Trist and Bamforth concluded that the types of demands placed on employees 
and employee participation in decision-making affected employee health. Therefore, while scientific management approaches may have increased efficiency (at least in the short term), these improvements seemed to be offset by negative individual outcomes (Humphrey, Nargahng, \& Morgeson, 2007). Based on these findings, the sociotechnical systems theory (Trist, 1981) emerged. This approach stressed the importance of the optimization of the interaction between people and technology in the workplace. Specifically, research suggested that optimal organizational functioning would occur only if the social and technical systems were designed to complement each other (Trist, 1981).

After sociotechnical systems theory, the next major development in job design was the emergence of Herzberg's two-factor (motivation/hygiene) theory of work. According to Herzberg (1966), the factors that lead to job satisfaction (motivation factors) are different from the factors that lead to job dissatisfaction (hygiene factors). Motivation factors include intrinsic aspects of the job itself, such as recognition, challenge, responsibility, and opportunity for advancement. Conversely, hygiene factors, like work conditions, company policies, pay, and relationships are extrinsic factors, related to the context of work (features of the work environment). While popular when it emerged, Herzberg's two-factor theory of work has been somewhat discredited in recent research (Morgeson \& Campion, 2003). The major disadvantage of this approach is its lack of methodological rigor; Dunnette, Campbell, and Hakel (1967) noted that Herzberg's results may have been more indicative of the method used to collect the data (critical incident method) than an actual representation of the constructs. Still, the twofactor model had a large impact on subsequent research on job design, in that Herzberg's 
conceptualization of motivation factors led subsequent researchers to focus on intrinsic aspects of the job, which were believed to have the most impact on outcomes.

Accordingly, job enrichment approaches, which emerged out of Herzberg's theory, involve increasing the motivation factors of a job. According to Parker and Wall (1998), job enrichment can take two forms: allowing employees to take on some of the decisions usually made by the supervisors, and "upgrading" jobs to include extra skilled tasks. It is important to note that enrichment does not simply mean enlargement. Enrichment involves vertical expansion of a job (greater responsibility), while enlargement involves horizontal expansion of a job (simply increasing the number of tasks assigned). Ways to enrich jobs include providing employees feedback on their performance, providing task variety, and allowing autonomy (Parker \& Wall, 1998).

Hackman and Oldham's Job Characteristics Model (JCM; 1975) also focuses on the motivational aspects of work and became one of the most influential job enrichment models. The JCM was developed in order to address the deficiencies of previous job design approaches and became one of the most pivotal theories of job design, and is still utilized today. The approach sought to enhance the efficacy of job enrichment by developing a more rigorous method for measuring and classifying job design. Hackman and Oldham's model focused on five intrinsic job characteristics: autonomy, skill variety, task identity, task significance, and feedback from the job itself. First, autonomy refers to the degree of freedom, independence, and discretion given to workers in scheduling work and determining procedures. Feedback is defined as the degree to which the employee is able to obtain information regarding their performance from the work itself. Skill variety 
refers to the variety of activities and use of variety of skills required by a job. Task identity refers to the degree to which a job supplies a visible outcome of the work or the degree to which the job requires completion of a whole piece of work. Finally, task significance refers to the extent to which the job impacts the lives and work of other people. They proposed that the enrichment of the five characteristics would lead to three critical psychological states: experienced meaningfulness, responsibility, and knowledge of results. These three psychological states in turn lead to the outcomes of work motivation, performance quality, job and growth satisfaction, and low absenteeism and turnover.

A few years later, Karasek's Job Demands-Control (JD-C) model (1979) showed that jobs that are high in demand and low in control (decision latitude) are related to high strain and low job satisfaction. While this model was created around the same time as the JCM, it proposed a unique approach, because it focused on the broader construct of job stressors rather than specific job characteristics. According to the JD-C model, enhanced job control was thought to buffer the negative effects of job demands on employee physical and mental health. Social support (Karasek \& Theorell, 1990) and job resources (characteristics that facilitate growth and achievement; Demerouti, Bakker, Nachreiner, \& Schaufeli, 2001) have also been shown to mitigate the effects of high demands on strain. Consistent support has been found for the main effects of the JD-C model: High job demands generally lead to increased stress, while high control and resources generally lead to less stress. However, there has been a lack of support for the interaction 
effect of job demands and resources (de Lange, Taris, Kompier, Houtman, \& Bongers, 2003).

Perhaps the most comprehensive job design measure utilized in current job design research is Morgeson and Humphrey's Work Design Questionnaire (WDQ, 2006). The WDQ can be viewed as a compilation of the constructs evaluated in previous job design models, as it is the most comprehensive model designed to date. This model integrates motivational, social, and work context characteristics, an approach traditionally not utilized in job design research. In developing the WDQ, 21 key work characteristics were identified and placed into three major categories: motivational, social, and contextual. Motivational work characteristics include both task characteristics (e.g. autonomy and task significance) and knowledge characteristics (e.g. skill variety and specialization). Social characteristics include features like interdependence and social support, while contextual characteristics include elements such as ergonomics and work conditions. In validating the WDQ, Morgeson and Humphrey found that both task and knowledge characteristics were positively related to satisfaction, while only knowledge characteristics were positively related to training and compensation requirements. They also found that social support incrementally predicted satisfaction beyond motivational work characteristics. The advantages of Morgeson and Humphrey's approach are that it captures both task and attribute measures; acknowledges both the job itself and the link between jobs and the broader environment; and includes a wider variety of job characteristics than previous models of job design. 
Regardless of the particular theory examined, research has almost unequivocally shown that job design is related to a variety of individual, group, and organizational outcomes (Morgeson \& Campion, 2003; Morgeson \& Humphrey, 2006). At the individual level, studies have shown that job design affects employees' job satisfaction, depression levels, and emotional exhaustion (de Lange et al., 2003); engagement in counterproductive work behaviors and organizational citizenship behaviors (Rodell \& Judge, 2009); vigor (Van Den Broek, De Cuyper, De Witte, \& Vansteenkiste, 2010); motivation to learn and learning performance (LePine, LePine, \& Jackson, 2004); job performance, job dedication, and helping behavior (Grant, 2008); self-reported health and health behaviors, such as smoking and alcohol consumption (Wilson, DeJoy, Vandenberg, Richardson, \& McGrath, 2004); and cardiovascular health (Aboa-Éboulé, Brisson, Maunsell, Mâsse, Bourbonnais, Vézina, Milot, Théroux, \& Dagenais, 2007). Additionally, a recent meta-analysis by Humphrey, Nahrgang, and Morgeson (2007) highlighted the extent to which job characteristics (in particular, those delineated in the WDQ) affect a wide variety of outcomes. Results from their review of 259 studies and 219,625 participants showed that 14 work characteristics explained, on average, $43 \%$ of the variance in the 19 worker attitudes and behaviors examined. Motivational, social, and work context characteristics were found to significantly predict subjective performance, turnover intentions, job satisfaction, organizational commitment, and role perception outcomes. Relevant to the current study, Humphrey and colleagues (2007) found that all four social characteristics (interdependence, feedback from others, social support, and interaction outside the organization) were related to job satisfaction. 
Furthermore, interdependence, feedback from others, and social support were related to supervisor satisfaction, coworker satisfaction, compensation satisfaction, and promotion satisfaction. Interdependence and social support were both related to organizational commitment; interdependence and feedback from others were related to job involvement; and interdependence, feedback from others, and social support were all related to internal work motivation. Perhaps most relevant to the current study, social characteristics were related to important individual well-being outcomes. Social support was negatively related to role ambiguity, role conflict, anxiety, and overload. Interdependence, feedback from others, and social support were negatively related to stress, while feedback from others and social support were negatively related to burnout/exhaustion.

The nature of one's job is clearly relevant to both organizational and individual outcomes. Thus, the need for researchers and practitioners to gain a more comprehensive understanding of the effects of job design is evident. In fact, recent publications have explicitly called for research on individual differences as they influence behavioral and attitudinal reactions to job characteristics (Grant, Fried, \& Juillerat, 2010). To this end, moderators in the relationship between job characteristics and worker outcomes should be examined. Although scholars have noted that few studies to date have done this (Grant, Fried, \& Juillerat, 2010), preliminary research has begun to show that individual differences, such as age, may be important to understanding these relationships. For example, Zacher, Heusner, Schmitz, Zwierzanska, and Frese (2010) found that age and job complexity can interact to affect perceived opportunities at work. Further, Zaniboni, Truxillo, Fraccaroli, McCune, and Bertolino (2011) found that age moderates the 
relationship between job characteristics (task variety and interaction outside the organization) and both job satisfaction and engagement. Age may also moderate how some aspects of the work environment are perceived. For example, the same environmental factors may be viewed as challenge stressors for some, and hindrance stressors for others, depending on age. In the present study, I will examine how job satisfaction and job tension are affected by the relationship between social job characteristics and age.

\section{Theoretical Approaches to Understanding Age at Work}

The lifespan development perspective can explain how the aging process affects job attitudes, stress, health, and well-being in the workplace. Lifespan development theory is based on the idea that patterns of change occur throughout the lifespan and that development involves adaptive processes including acquisition, maintenance, transformation, and attrition (Baltes et al., 1999). Kanfer and Ackerman's (2004) model of lifespan changes in work motivation, Selective Optimization and Compensation (SOC; Baltes \& Baltes, 1990) theory, and Socioemotional Selectivity (SES; Carstesen, 1991) theory have been used to explain results observed in the age and workplace literature. Each approach complements the other, and each is useful in explaining the worker age/job design interaction. In the current study, I will be using mostly SES theory in the formation of my hypotheses, but will review each approach to provide a better understanding of the aging workforce.

Kanfer and Ackerman's lifespan work motivation framework. Kanfer and Ackerman (2004) propose an age-focused framework for understanding changes in work 
motivation over the lifespan. They identify four patterns of development that affect work motivation: (1) loss; (2) growth; (3) reorganization; and (4) exchange. Loss describes the negative relationship between age and certain abilities like fluid intelligence (e.g., working memory, abstract reasoning, and attention). Growth describes the positive relationship between age and other resources such as crystallized, or experiential, knowledge. Reorganization refers to the changes in the organization, structure, and reprioritization of non-ability traits across adulthood. Exchange describes changes in tendencies through the lifespan, such as changes in personality (Roberts, Wood, \& Viechtbauer, 2006; Robins, Trzesniewski, Tracy, Gosling, \& Potter, 2002) that affect work motivation. This framework suggests that the same job characteristic may be differentially motivating for older and younger workers, depending on the skills it requires. This view of age and work motivation gained support in a recent meta-analysis (Kooij, Lange, Jansen, Kanfer, \& Dikkers, 2011): Age was found to be positively related to intrinsic motives but negatively related to growth and extrinsic motives.

Selective optimization and compensation. SOC (Baltes \& Baltes, 1990) is a lifespan theory that outlines three adaptive strategies people use to fit their current resources to demands throughout the aging process (Baltes \& Baltes, 1990). First, selection involves making decisions about which goals and outcomes to pursue. When people realize that they lack the personal resources to maintain performance across work domains, they select specific goals and outcomes to successfully match their resources to demands. Second, after goals and outcomes are identified, people allocate their efforts and resources to optimize their performance. Lastly, to compensate for age-related 
declines, people search for compensation strategies to maintain a certain level of performance. Therefore, selection, optimization, and compensation processes explain the strategies people use to allocate their resources to adapt to personal age-related changes as well as to changes occurring in the workplace (Baltes \& Dickson, 2001).

Socioemotional selectivity theory. While SOC theory describes three processes that influence adaptive behavior, SES (Carstensen et al., 1999) focuses on the selection processes and purports that people's perception of time is critical in the selection and pursuit of social goals (Carstesen et al., 1999). It proposes two types of social goals: Those related to the acquisition of knowledge, and those related to emotion regulation. The cornerstone of SES theory is that when time is perceived as being open-ended (one has much of their life ahead of them), knowledge-related goals are given a higher priority. Conversely, when time is perceived as limited (as in older workers), the person takes a more present-oriented perspective and emotional goals are given a higher priority. Therefore, job design features that are likely to increase work-related knowledge should be more appealing to younger workers, while job characteristics that allow workers the opportunity for meaningful social interaction should be more appealing to older workers. $\mathrm{Ng}$ and Feldman (2010) interpret the findings of their meta-analysis, which showed a positive relationship between age and most job attitudes, in the context of SES theory (Carstensen et al., 1999) in two ways. First, while younger people are more likely than older people to believe that they have time and opportunities remaining, older people may see some limits to their future options. Thus, older adults focus more on interpersonal activities rather than knowledge acquisition. Second, older people are more likely to 
have more positive experiences than their younger counterparts because, with their perceived time limitations, they do not have time for negative emotions.

\section{Age and Job Design}

Conceptualizations of age. When evaluating the role of age in its effects on outcomes, and particularly as a moderator between job design characteristics and outcomes, it is important to define what is meant by age. Because of its concreteness and simplicity, chronological age has been the predominant age construct used in research and policy-making (Settersten \& Mayer, 1997). This approach can also be useful for organizational decision-makers. However, because chronological age is a marker for other variables such as self-concept and employee health, examining only chronological age may be limiting: It does not take into account differences in life experiences, social and cultural influences, and individuals' own interpretations of their aging processes (Adams, 1971). Furthermore, as people grow older, variability among similarly-aged individuals increases (Dannefer, 1987), and simple chronological age becomes less useful as an index for understanding the key variables in the older worker (Settersten \& Mayer, 1997).

Accordingly, Birren and Cunningham (1985) suggested that alternative measures that are more sensitive to individual differences be developed. Specifically, they discussed three types of age: biological age, which is a person's present position with respect to their potential lifespan; social age, which is defined as a person's roles and habits with respect to other members of their society; and psychological age, which refers to the behavioral capacities of individuals to adapt to changing demands. From a research 
point of view, the major advantage of Birren and Cunningham's conceptualization of age is that it is multifaceted, and takes into account the complexity of aging.

Self-evaluated age has since been conceptualized in a variety of ways. For example, Barak (1987) categorized self-evaluated age into three categories-ideal age concepts, attitudes towards age identity, and age-role self-concepts. Ideal age refers to the age that an individual considers to be optimal. Research has shown that a person's ideal age tends to be younger than their chronological age (Barak \& Gould, 1985). Morale age has been defined as a person's level of satisfaction with their personal age status (Barak, 1987). Lastly, age-role self-concepts address the relationship between one's age concept and one's self-concept.

One of the most multifaceted conceptualizations of subjective age is personal age, which refers to how old one perceives him- or herself to be relative to their own chronological age (Kastenbaum, Derbin, Sabatini, \& Artt, 1972). Katstenbaum and colleagues measured four dimensions of personal age, using a 49-item structured interview technique. These dimensions were later simplified by Barak and Stern (1986), and renamed cognitive age. Cognitive age is evaluated with single-item measures for each dimension: feel age ("I feel as though I am in my..."), look age ("I look as though I am in my...”), do age ("I do most things as though I were in my..."), and interest age ("My interests are mostly those of a person in his/her."). Response options are "twenties", "thirties", etc. The construct of cognitive age has been supported empirically; research has shown that it is correlated with health, demographic variables, psychosocial traits, and behaviors (Barak and Stern, 1986). 
Another popular method for assessing self-evaluated age is comparative or relative age identification. In this case, respondents are asked whether they feel older, younger, or the same as others in a specific context. (It is important to note the difference between comparative age and personal age; with personal age, one evaluates how old they perceive themselves to be compared to their own chronological age, while with comparative age, the comparison is made to a group of others within a context.) However, research has yet to show if this is practically different from asking respondents to simply evaluate how they view themselves compared to their chronological age (Settersten \& Mayer, 1997).

While self-evaluated age has been utilized in other disciplines, it is relatively new to the Industrial/Organizational Psychology literature. However, existing research has shown that measures of psychological age constructs are related to organizational commitment, job satisfaction, self-evaluations of performance, and reports of workrelated stress (Barnes-Farrell, Rumery, \& Swody, 2002). For example, in one study, discrepancy between personal age (how old a worker feels) and calendar age was systematically related to the presence of workplace stressors and reports of workplace strains. Specifically, workers who reported a personal age older than their calendar age reported higher levels of workplace stressors and higher levels of work strain (tension, fatigue, and decreased job performance) than workers who reported a personal age younger than their calendar age (Barnes-Farrell \& Piotrowski, 1991).

In the current study, chronological age is used as the moderating variable. However, in recognition of the fact that differences in life experiences, social and cultural 
influences, and individuals' own interpretations of their aging processes affect the age one perceives him- or herself to be, comparative age (Settersten \& Mayer, 1997) will be used in an examination of the relationship between job characteristics and age in a set of related research questions. Comparative age is used in the current research over other measures of subjective age because it focuses employees' frame-of-reference when they are making their age evaluation, while other measures ignore the context being used to make an age evaluation (Cadiz, 2009). A measure that asks respondents to think about their age in relation to others at work is likely to be more predictive of work-related outcomes than other measures of subjective age.

Age and worker outcomes. Research has generally shown that older workers report more positive job attitudes and behaviors than their younger counterparts. $\mathrm{Ng}$ and Feldman (2008) found that older workers tend to engage in more citizenship and safetyrelated behaviors and less counterproductive work behaviors than their younger counterparts. More recently, Ng and Feldman (2010) examined the age-job attitude relationship meta-analytically, finding that age was related to improvement in most of the 35 job attitudes examined. For example, age was positively related to job satisfaction, organizational commitment, and perceived control, and negatively related to role overload, emotional exhaustion, and job demands, although some of these effect sizes were small. Ng and Feldman (2010) interpret their findings in the context of SES theory (Carstensen et al., 1999). First, due to perceived time limits to their future options, older adults focus more on interpersonal activities rather than knowledge acquisition. Second, older people are more likely to have more positive experiences than their younger 
counterparts because, with their perceived time limitations, they believe that they do not have time for negative emotions. This positive affect among older adults is consistent with research in developmental psychology (Sullivan, Mikels, \& Carstensen, 2010) and with the finding that well-being and life satisfaction appear to increase with age, despite declines in objective health (e.g., Diener \& Suh, 1997).

\section{Hypotheses}

While both age and job characteristics can affect worker outcomes such as job satisfaction, recent reviews have suggested that the effects of job characteristics may be moderated by individual differences (Grant, 2008) and time-related variables such as career stage (Fried et al., 2007). However, such empirical studies are relatively limited to date. The current study will examine the role of age as a moderator in the relationship between job characteristics (specifically, the social job characteristics delineated in the WDQ [social support, interdependence, interaction outside the organization, and feedback from others] and a new construct, given social support) and worker outcomes (job satisfaction and job tension).

I have chosen to investigate the effects of the social job characteristics, as opposed to the task and knowledge characteristics in the WDQ, because they are the most likely to have differential effects on workers depending on age. (I am not investigating the contextual characteristics of the WDQ because they focus on physical characteristics of the job, such as physical demands and ergonomics. These characteristics are less likely to be explained by psychological theory; instead, one would expect that poor physical 
working conditions would be related to more negative outcomes for all workers [even moreso for older workers because of declines in physical ability/stamina]). The social characteristics are the most likely to have varying effects on older and younger workers because of their relation to theories of aging, which place importance on emotion throughout the lifespan. In a summary of the effects of job characteristics on older versus younger workers, $\mathrm{Ng}$ and Feldman (2010) suggested that environments that lead to more positive job attitudes for older workers are those that are emotionally rewarding and socially supportive. Additional research has also supported the idea that older workers are more interested in the social and emotional aspects of work (Ebner, Freund, \& Baltes, 2006; Freund, 2006; Kanfer \& Ackerman, 2004). Lastly, in a chapter examining job design (as outlined by the WDQ) from an aging perspective, Truxillo, Cadiz, and Rineer (2012) provided strong theoretical support for the proposition that social characteristics should have differential effects on younger and older workers.

Social support. Social support is defined as the degree to which the job provides opportunities for advice and assistance from others (Morgeson \& Humphrey, 2006). Examples of the social support characteristic include coworker and supervisor support as well as opportunities for friendship. It has been proposed that social support buffers the effects of negative work outcomes (Karasek, Brisson, Kawakami, Houtman, Bongers, \& Amick, 1998). Research has shown that social support has both a direct effect on wellbeing, as well as a protective effect against the potentially-harmful impact of negative events (Cohen \& Wills, 1985). Furthermore, social support has a predictive relationship with physical health (House, Landis, \& Umberson, 1988). Meta-analytic research 
supports the social support buffering effect on variables such as role overload, stress, and burnout (Humphrey et al., 2007) and the positive effects of social support on job attitudes (Humphrey et al., 2007).

Interestingly, a distinction between social support that is given and received is generally not made when discussing this characteristic. The opportunity to give social support to others may be more salient and desirable to older workers. As workers age, they may value social support more than their younger colleagues because they are more motivated by emotionally-related goals like maintaining social relationships (Truxillo, Cadiz, \& Rineer, 2012). According to SES theory, as people age they place higher priority on emotional goals (Carstesen et al., 1999), and opportunities to give social support could potentially fulfill the generative need that increases through the lifespan (Kanfer \& Ackerman, 2004). Because none of the items assessing social support in the WDQ address the opportunity to give social support to others, I have created a Given Social Support subscale to measure this construct. ${ }^{1}$ (Please see the first two measures under Questionnaire Measures in Appendix A to see the items used in both the original WDQ social support subscale and the new given social support subscale.) This is a new contribution to the existing work on job design and aging workers, as no such construct has previously been measured. In contrast to giving social support, I expect that receiving social support (the type of social support described in the WDQ) should be generally perceived as a positive way to cope with difficult situations regardless of a person's age,

\footnotetext{
${ }^{1}$ Thanks to David Cadiz for developing (and sharing with me) the idea of differentiating between given and received social support.
} 
but will be more beneficial for younger workers, who may need more guidance than older workers.

Hypothesis 1a: Age moderates the relationship between given social support and job satisfaction. Specifically, there will be a stronger positive relationship between given social support and job satisfaction for older workers than for younger workers.

Hypothesis 1b: Age moderates the relationship between given social support and job tension. Specifically, there will be a stronger negative relationship between given social support and job tension for older workers than for younger workers.

Hypothesis 1c: Age moderates the relationship between social support and job satisfaction. Specifically, the positive relationship between social support and job satisfaction should be stronger for younger workers than older workers.

Hypothesis 1d: Age moderates the relationship between social support and job tension. Specifically, the negative relationship between social support and job tension should be stronger for younger workers than older workers.

Interdependence. Interdependence is a multi-faceted construct that reflects how connected one's job is to others' jobs (Morgeson \& Humphrey, 2006; Saavedra, Earley, \& Van Dyne, 1993). It represents the extent to which a job is dependent on others' work and other jobs depend on the focal job. Research has shown that interdependence is positively related to attitudinal variables including job satisfaction, satisfaction with 
coworkers and supervisors, and organizational commitment (Humphrey et al., 2007). It is also important because the positive relationship between group efficacy and performance is strongest under conditions of high interdependence (Gully et al., 2002).

Interdependence may create a more complex and motivating job because it requires increased interactions with coworkers in order to complete work (Kiggundu, 1983). It may be more appealing to older workers because it allows them to use their crystallized intelligence (Kanfer \& Ackerman, 2004), as it provides greater opportunities to pass on previous work experiences and knowledge to coworkers. Furthermore, the increased interactions could be more attractive to older workers because they make the job more relational, thus fulfilling the desire for emotional connectivity and to feel more socially integrated, as suggested by SES theory (Carstesen et al., 1999). Conversely, however, SES would also support the argument that younger workers would enjoy increased required interactions to the extent that it fulfills their desire to build knowledge (Carstesen et al., 1999).

Research Question 1a: Will age moderate the relationship between interdependence and job satisfaction?

Research Question 1b: Will age moderate the relationship between interdependence and job tension?

Interaction outside the organization. Interaction outside the organization reflects the amount of interaction that the job requires with people external to the organization (Morgeson \& Humphrey, 2006). This characteristic is different from the other social characteristics because it considers the broader social context outside of the 
organization. Furthermore, less is known about this characteristic because it has received less research attention than any of the other social characteristics. SES theory could provide the theoretical argument for how workers of different ages would react to interactions external to the organization. Younger workers have a more future-oriented time perspective, and therefore, would place greater priority on seeking knowledge from a large number of social relationships (Carstesen et al., 1999). As proposed by Truxillo, Cadiz, and Rineer (2012), increased external interactions would increase access to a broader range of individuals, which would allow younger workers to invest in a wide range of relationships to network and gather information.

Conversely, older workers would have less desire to have a broad range of relationships and would rather focus on strengthening existing relationships. Furthermore, interaction outside the organization may be stressful to older workers because it can require emotional labor, which involves enhancing, faking, or suppressing emotions to modify the emotional expression (Grandey, 2000). Many workplaces have implicit and/or explicit rules regarding how employees should interact with the public (Diefendorff, Richard, \& Croyle, 2006). While often beneficial for the company, emotional labor can be stressful and lead to burnout for the individual (Hochschild, 1983). It is important to note that the relationship between interaction outside the organization and individual outcomes may be moderated by individual differences such as extraversion. In general, however, based on the theory above, I propose that a positive relationship between interactions outside the organization and worker outcomes will exist 
for younger workers, but that no relationship or even a negative relationship may exist for older workers.

Hypothesis 2a: Age will moderate the relationship between interaction outside the organization and job satisfaction, such that the relationship between interaction outside the organization and job satisfaction will be positive for younger employees, and null or negative for older employees.

Hypothesis2b: Age will moderate the relationship between interaction outside the organization and job tension, such that the relationship between interaction outside the organization and job tension will be negative for younger employees, and null or positive for older employees.

Feedback from others. Feedback from others represents the extent to which others provide information about one's performance (Morgeson \& Humphrey, 2006). This is different from receiving feedback from the job itself as described by Hackman and Oldham (1975). In fact, research has found that feedback from others and feedback from the job are only moderately related (Morgeson \& Humphrey, 2006). Desire for feedback may be influenced by individual differences in need to reduce uncertainty (Ashford \& Cummings, 1983), public self-consciousness, and self-esteem (Levy, Albright, Cawley, \& Williams, 1995). However, Humphrey and colleagues (2007) found that, in general, feedback from others is positively related to job satisfaction and wellbeing outcomes (i.e., less stress and burnout). Feedback from others may appeal more to younger workers because they need others' feedback for growth and development. 
Therefore, I expect that feedback from others will be more important for younger workers.

Hypothesis 3a: Age will moderate the relationship between feedback from others and job satisfaction, such that the positive relationship between feedback from others and job satisfaction will be stronger for younger workers. Hypothesis 3b: Age will moderate the relationship between feedback from others and job tension, such that the negative relationship between feedback from others and job tension will be stronger for younger workers.

\section{Additional Research Questions}

I decided to focus on chronological age in my hypotheses, despite its limitations, because of its practicality. Chronological age is straightforward and easy to define. Furthermore, if the goal of research is to eventually make recommendations that can be utilized in practice, at the present time it makes more sense to make recommendations based on chronological age. (Organizations are much more likely to know their employees' chronological age than they are to know how old they feel or how they feel about their age.) However, measures of subjective age are important in understanding the experience of the aging worker. I have chosen to use comparative age as opposed to other measures of subjective age because it takes context into account and is conceptually different from chronological age. Comparative age is particularly important when considered in light of relational demography, which explains that people compare their own demographic characteristics (race, gender, age, etc.) with those of others in their social contexts to determine how similar or dissimilar they are to others (Tsui, Egan, \& 
O'Reilly, 1992). The level of similarity or dissimilarity then affects work-related attitudes (Riordian \& Shore, 1997). Comparative age also provides an "at-work" frame of reference for respondents, which has been shown to increase the validity of scales used in organizational research (Hunthausen, Truxillo, Bauer, \& Hammer, 2003). Accordingly, my research questions are as follows:

Research Question 2 (a-b): Will comparative age moderate the relationship between given social support and (a) job satisfaction and (b) job tension? Research Question $2(c-d)$ : Will comparative age moderate the relationship between social support and (a) job satisfaction and (b) job tension?

Research Question $3(a-b)$ : Will comparative age moderate the relationship between interdependence and (a) job satisfaction and (b) job tension?

Research Question $4(a-b)$ : Will comparative age moderate the relationship between interaction outside the organization and (a) job satisfaction and (b) job tension?

Research Question $5(a-b)$ : Will comparative age moderate the relationship between feedback from others and (a) job satisfaction and (b) job tension? 


\section{Chapter 2}

Method

\section{Participants and Procedures}

Data for the current study was collected as part of a larger research and intervention project on work, family, safety, and health with employees at the Portland Water Bureau's downtown office. The sample consisted of 186 employees (out of a total of 387 employees; response rate was $48 \%$ ). Sixty percent were male and $40 \%$ were female. The majority $(88 \%)$ of the employees were white, and the mean age was 49 (ages ranged from 27-64). Approximately one third (34.9\%) of participants had some college or associate's degree, while $63.4 \%$ had a bachelor's degree or higher. Participants holding supervisory or managerial roles made up $55.3 \%$ of the sample, and the average tenure at the Water Bureau was 11.6 years. Employees worked in the following departments: Engineering, Customer Service, Administration, Operations, and Resources \& Protection. Sample job titles held included Principle Engineer, Customer Service Supervisor, Administrative Assistant, and Business Operations Supervisor.

Several measures were taken to increase the response rate: the invitation to participate was sent by the Director of the Water Bureau; participants were given a chance to win one of six \$50 Visa Gift Cards; and a reminder email was sent half-way through the administration of the survey to remind employees to participate. Further, the invitation to participate from the Director of the Water Bureau included a short explanation of our work, and explained that the results of the study would be used to change practices to improve the well-being of employees. The survey was administered 
online, and participation was voluntary. The consent letter utilized in this study is in Appendix B.

\section{Measures}

Social job characteristics. Social job characteristics were measured with the Work Design Questionnaire (WDQ; Morgeson \& Humphrey, 2006). Morgeson and Humphrey (2006) distinguish between four social characteristics of a job: social support, interdependence, interaction outside the organization, and feedback from others. These categories reflect different ways that social interactions are integrated into a job. There were six items assessing social support (sample item: "My supervisor is concerned about the welfare of the people that work for him/her"); six items assessing interdependence (“Other jobs depend directly on my job"); four items assessing interaction outside the organization ("The job involves interaction with people who are not members of my organization"); and three items assessing feedback from others ("I receive a great deal of information from my manager and coworkers about my job performance"). Because none of the items assessing social support addressed the opportunity to give social support to others, I created three items (based on the social support construct in the WDQ that assess received social support) for the purpose of measuring this construct: "My job allows me to help my coworkers", "My job allows me to take an interest in coworkers", and "I have an opportunity to help others at work". These items were developed by Donald Truxillo and Jennifer Rineer, based on an understanding of the social support construct. Specifically, we developed this subscale using aspects of given social support that are likely to differentiate older and younger workers according to SES theory. Responses to 
items were provided on a five-point Likert scale $(1=$ "strongly disagree" to $5=$ "strongly agree"). Cronbach's alphas for the Social Job Characteristics subscales ranged from .7791 .

Job tension and job satisfaction. I measured both job tension and job satisfaction as indicators of well-being. Job tension was assessed using House and Rizzo's 7-item measure of job tension (1972). This measure describes an employee's psychological and psychosomatic symptoms associated with tension experienced at work. Cronbach's alpha for the scale in this study was .84. A sample item is "Problems associated with my job have kept me awake at night”. Job satisfaction was measured using a 5-item version of Brayfield and Rothe's (1951) Job Satisfaction Scale used by Judge et al. (2001). This measure is designed to measure global job satisfaction. Cronbach's alpha with this sample was .90. A sample item is "I find real enjoyment in my work". Responses to items for both measures were provided on a five-point Likert scale ( 1 = "strongly disagree" to 5 = "strongly agree").

Age. Participants were asked to report their chronological age (in years). I also assessed subjective age with Cleveland and Shore's (1992) measure of Comparative Age. Comparative Age is measured with one item: "In comparison to my coworkers, I would describe myself as being___. Response options are "Much Younger", "Younger", "Neither Younger nor Older", "Older", and "Much Older".

Control variables. I also assessed various demographic variables, such as job tenure, managerial status, and race. In preliminary data analyses, control variables were identified based on their relationships with study variables and their theoretical 
importance based on past research. A preliminary analysis of the data was conducted to confirm compliance with the assumptions of multiple regression and to assure that statistical outliers were present. 


\section{Chapter 3 \\ Results}

\section{Preliminary Analysis}

Table 1 shows means, standard deviations, intercorrelations, and reliabilities of study variables. While over half of the social job characteristics were significantly correlated with job satisfaction (feedback from others: $r=.21, p<.01$; given social support: $r=.57, p<.01$; social support: $r=.58, p<.01)$ and job tension (interdependence: $r=.16, p<.05$; given social support: $r=-.27, p<.01$; social support: $r$ $=-.36, p<.01)$, neither chronological nor comparative age were significantly correlated with the outcome variables (correlations ranged from .03-.14). Job tension and job satisfaction were significantly, but not highly correlated $(r=-.33, p<.01)$, suggesting that they are related, but distinct constructs. Chronological and comparative age were very highly and significantly correlated $(r=.83, p<.01)$. Factor analyses were conducted on each predictor and outcome variable; results demonstrated that items loaded as expected. Further, factor analysis on given social support and the traditional measure of social support (received social support) showed that the two-factor model (CFI $=.871$, RMSEA $=.135)$ fit better than the one-factor model $(\mathrm{CFI}=.781$, RMSEA $=.172)$, providing justification for analyzing the two separately.

\section{Hypothesis Testing}

The purpose of the current study was to examine the role of age as a moderator in the relationship between social job characteristics and job satisfaction and job tension. I 
used moderated regression analyses to test the proposed hypotheses. Moderated regression allowed me to examine the effect of a third variable on the relationship between an independent variable and a dependent variable. In the first regression equation, job satisfaction was regressed onto the job characteristic and age. Control variables (education level, job tenure, income level, union membership, and supervisory status) were entered in Step 1 of the regression analysis. In Step 2, the centered job characteristic was entered into the equation. A significant $\beta(\mathrm{p}<.05)$, in this step indicated that the independent variable (the job characteristic) explained significant variance in the outcome variable (job satisfaction), as determined by $R^{2}$. Age was entered in the third step of the analysis. A significant $\beta(\mathrm{p}<.05)$ at this step in the regression indicated that when adjusting for the control variables, both predictors (the job characteristic and age) accounted for significant variance in job satisfaction. $\Delta R^{2}$ was examined to determine the incremental variance explained by age over and above that of the independent variable (the job characteristic) and the control variables. In the final and focal step, the interaction term (job characteristic $\times$ age) was entered into the regression equation. A significant $\Delta R^{2}$ in this step indicated that additional variance in job satisfaction was explained by the interaction term. This indicated that age does moderate the relationship between the job characteristic and job satisfaction. This procedure was conducted for each job characteristic (given social support, social support, interdependence, interaction outside the organization, and feedback from others). Next, the same analyses were performed using job tension as the outcome variable. To address my research questions, I conducted the same analyses using subjective age (comparative age) in place of 
chronological age. This allowed me to see whether the results of the moderation analyses were similar using subjective age. I graphed all significant interactions.

The independent and moderating variables (job satisfaction, job tension, and the five social job characteristics) were standardized in order to center them, reducing potential issues of multicollinearity (Tabachnick \& Fidell, 2007). Also, centering improves interpretability by avoiding the problem of evaluating one main effect at an extreme value of the other main effect (Howell, 2010). A summary of the results of the regression analyses are presented in Table 2. Detailed results of the hierarchical multiple regression analyses conducted to address all of the hypotheses and research questions are presented in Tables 3-7.

Hypothesis 1a (Table 3) predicted that age would moderate the relationship between given social support and job satisfaction, such that there would be a stronger positive relationship between given social support and job satisfaction for older workers than for younger workers. This hypothesis was not supported. There was a significant main effect of given social support on job satisfaction $(\beta=.32, t(147)=6.17, p<.01)$, but no main effect of age on job satisfaction. The interaction between age and social support was marginally significant in increasing the prediction of job satisfaction, though not in the direction hypothesized $\left(\beta=-.08, F(1,147)=2.82, p=.09, \Delta R^{2}=.01\right)$. As shown in Figure 2, an increase in given social support led to a greater increase in job satisfaction for younger employees. 
According to Hypothesis $1 \mathrm{~b}$ (Table 3), age would moderate the relationship between given social support and job tension. Specifically, there should be a stronger negative relationship between given social support and job tension for older workers than for younger workers. This hypothesis was supported. In addition to a significant main effect of given social support on job tension $(\beta=-.21, t(147)=-3.49, p<.01)$, there was a significant increase in $R^{2}$ with the addition of the interaction term $(\beta=-.15, F(1,147)$ $=8.29, p<.01, \Delta R^{2}=.05$ ). (There was no significant main effect of age on given social support.) As can be seen in Figure 3, an increase in given social support had virtually no effect on younger employees, but led to a decrease in job tension for older employees.

Hypothesis 1c (Table 4) stated that age would moderate the relationship between social support and job satisfaction (specifically, that the positive relationship between social support and job satisfaction should be stronger for younger workers than older workers). This hypothesis was not supported. There was a significant main effect of social support on job satisfaction $(\beta=.35, t(147)=6.49, p<.01)$, but neither the main effect of age nor the interaction of age and social support $(\beta=-.01, F(1,147)=.05, p$ $\left.=.82, \Delta R^{2}=.00\right)$ had a significant effect on job satisfaction.

Hypothesis 1d (Table 4) proposed that age would moderate the relationship between social support and job tension. Specifically, the negative relationship between social support and job tension should be stronger for younger workers than older workers. This relationship was not supported. There was a significant main effect of social support on job tension $(\beta=-.30, t(147)=-5.23, p<.01)$, but no significant main effect of age. 
The interaction of age and social support significantly increased the prediction of job tension $\left(\beta=-.20, F(1,147)=11.68, p<.01, \Delta R^{2}=.06\right)$, but not in the direction hypothesized. As seen in Figure 4, an increase in social support led to a greater decrease in job tension for older employees than for younger employees.

The relationships using interdependence as a predictor variable (Table 4) were posed as research questions, as the existing literature did not provide clear direction as to how age might moderate those relationships. Research Question 1a asked if age would moderate the relationship between interdependence and job satisfaction, while Research Question $1 \mathrm{~b}$ addressed whether or not age would moderate the relationship between interdependence and job tension. In both cases, there were neither significant main effects of interdependence $(\beta=.08, t(147)=1.43, p=.16$ for job satisfaction and $\beta=.08, t(147)$ $=1.45, p=.15$ for job tension) nor significant effects of the interaction of age and interdependence $\left(\beta=.01, F(1,147)=.02, p=.90, \Delta R^{2}=.00\right.$ for job satisfaction and $\beta=-$ $.02, F(1,147)=.10, p=.75, \Delta R^{2}=.00$ for job tension) on the outcomes. There were also no significant main effects of age on either job satisfaction or job tension in these relationships.

Hypothesis 2 a (Table 6) stated that age would moderate the relationship between interaction outside the organization and job satisfaction (specifically, that the relationship between interaction outside the organization and job satisfaction would be positive for younger employees, and null or negative for older employees). This hypothesis was not supported. Neither the main effect of interaction outside the organization $(\beta=.02, t(147)$ 
$=.39, p=.70)$, nor the interaction of age and interaction outside the organization $(\beta=-$ $\left..07, F(1,147)=1.78, p=.18, \Delta R^{2}=.01\right)$ had significant effects on job satisfaction.

Similarly, Hypothesis $2 \mathrm{~b}$ (Table 6) proposed that age would moderate the relationship between interaction outside the organization and job tension, such that the relationship between interaction outside the organization and job tension would be negative for younger employees, and null or positive for older employees. This hypothesis was also not supported. Neither the main effect of interaction outside the organization $(\beta=-.02, t(147)=.-.36, p=.72)$ nor the interaction of age and interaction outside the organization $\left(\beta=.03, F(1,147)=.23, p=.59, \Delta R^{2}=.00\right)$ had a significant effect on job tension.

Hypothesis 3a (Table 7) stated that age should moderate the relationship between feedback from others and job satisfaction, such that the positive relationship between feedback from others and job satisfaction would be stronger for younger workers. Hypothesis 3a was supported. There was a significant main effect of feedback from others on job satisfaction $(\beta=.15, t(147)=.-2.92, p<.01)$. Further, the $R^{2}$ was significantly increased by including the interaction term in the model $(\beta=-.122, F(1,147)$ $=5.51, p<.05, \Delta R^{2}=.03$ ). (There was no main effect of age on job satisfaction.) As can be seen in Figure 5, an increase in feedback had virtually no effect on job satisfaction for older employees, but led to an increase in job satisfaction for younger employees.

Hypothesis $3 b$ (Table 7) proposed that age should moderate the relationship between feedback from others and job tension (specifically, that the negative relationship 
between feedback from others and job tension would be stronger for younger workers). This relationship was not supported. Neither the main effect of feedback from others $(\beta=$ $-.06, t(147)=-1.07, p=.29)$ nor the interaction of feedback from others and age $(\beta=-.03$, $F(1,147)=.21, p=.65, \Delta R^{2}=.00$ ) had a significant impact on job tension. (There was also no main effect of age on job tension.)

\section{Additional Research Questions}

Research Question 2 (a-b) (Table 3) asked whether comparative age would moderate the relationship between given social support and (a) job satisfaction and (b) job tension. Although the interaction of comparative age and given social support was not significant in predicting job satisfaction $\left(\beta=-.015, F(1,147)=.10, p=.76, \Delta R^{2}=.00\right)$, it was significant in predicting job tension $\left(\beta=-.226, F(1,147)=18.35, p<.01, \Delta R^{2}=.10\right)$. The relationship addressed in Research Question 2b is illustrated in Figure 6; an increase in given social support had virtually no effect on those with younger comparative age, but led to a decrease in job tension for those with older comparative age.

Research Question 2 (c-d) (Table 4) asked whether comparative age would moderate the relationship between social support and (a) job satisfaction and (b) job tension. While the interaction of comparative age and given social support did not significantly predict job satisfaction $\left(\beta=.05, F(1,147)=.96, p=.33, \Delta R^{2}=.00\right)$, it did significantly predict job tension $\left(\beta=-.17, F(1,147)=8.56, p<.01, \Delta R^{2}=.05\right)$. As 
illustrated in Figure 7, an increase in social support led to a greater decrease in job tension for those with older comparative age.

Research Question 3 (a-b) (Table 5) asked whether comparative age would moderate the relationship between interdependence and (a) job satisfaction and (b) job tension. The interaction of interdependence and comparative age was not predictive of either job satisfaction $\left(\beta=.02, F(1,147)=.09, p=.77, \Delta R^{2}=.00\right)$ or job tension $(\beta=.01$, $\left.F(1,147)=.02, p=.88, \Delta R^{2}=.00\right)$.

Research Question 4 (a-b) (Table 6) asked whether comparative age would moderate the relationship between interaction outside the organization and (a) job satisfaction and (b) job tension. The interaction of interaction outside the organization and comparative age did significantly predict job satisfaction $(\beta=-.10, F(1,147)=4.48, p$ $\left.<.05, \Delta R^{2}=.03\right)$, but not job tension $\left(\beta=.05, F(1,147)=1.10, p=.30, \Delta R^{2}=.01\right)$. The interaction addressed in Research Question 4a is presented in Figure 8; an increase in interaction outside the organization led to an increase in job satisfaction for those with younger comparative age, but a decrease in job satisfaction for those with older comparative age.

Research Question 5 (a-b) (Table 7) asked whether comparative age would moderate the relationship between feedback from others and (a) job satisfaction and (b) job tension. The interaction between feedback from others and comparative age was borderline significant for job satisfaction $\left(\beta=-.10, F(1,147)=3.08, p=.08, \Delta R^{2}=.02\right)$, 
and not significant for job tension $\left(\beta=-.01, F(1,147)=.02, p=.90, \Delta R^{2}=.00\right)$. The relationship addressed in Research Question 5a is illustrated in Figure 9; an increase in feedback from others had virtually no effect on those with older comparative age, but led to an increase in job satisfaction for those with younger comparative age. 


\section{Chapter 4 \\ Discussion}

This study investigated the moderating effects of age (both chronological and subjective) on the relationship between social job characteristics and job satisfaction and job tension. It contributes to the existing literature in several important ways. First, it helps to identify job characteristics that increase job satisfaction and reduce job tension for older versus younger workers. This information has practical relevance: as the workforce ages, organizations that are able to develop jobs that accommodate workers across their lifespan will not only improve the attitudes and experiences of their workers, but also obtain a competitive advantage. Second, the new measure of given social support utilized in this study allows for a more nuanced view of the Social Support characteristic delineated in the WDQ. Lastly, this study leads to an increased understanding of the way in which subjective age affects employees' work experiences.

Using chronological age, three of the predicted interactions were significant (and in the hypothesized direction), and one was marginally significant (and in the hypothesized direction). Thus, overall, half of the hypotheses were supported. When chronological age was replaced with comparative age (a measure of subjective age), three of the interactions presented in the research questions were significant, and one was marginally significant. Furthermore, social job characteristics and age had differential effects on job satisfaction and job tension, supporting the notion that these outcomes are distinct constructs. In addition, although chronological age and subjective age were highly correlated, there were a few cases in which they differentially predicted the 
outcomes, showing that subjective age is not redundant with chronological age and may be useful to take into consideration in organizational studies.

\section{Social Job Design Characteristics}

Social support (given). Contrary to the hypothesis, the newly developed measure of given social support - the opportunity to provide social support to others - led to greater job satisfaction for younger workers than for older workers, although this interaction between given social support and age was only marginally significant. This could be explained if given social support is simply a proxy for increased social interaction at work. The opportunity to give social support at work would only be present if there were opportunities to interact with colleagues; this is likely important to new employees, as they strive to gain knowledge and find their place in the organization. The interaction between given social support and age was in the expected direction when using job tension as an outcome, however. An increase in given social support led to a decrease in job tension for older employees, but had no effect on younger employees. This is what was expected through the lens of SES theory; as people age, they place higher priority on emotional goals (Carstesen et al., 1999). Opportunities to give social support could help to fulfill the generative need that increases through the lifespan (Kanfer \& Ackerman, 2004). When using subjective age as the moderator, the interaction between given social support and age was not significant in predicting job satisfaction, but was significant in predicting job tension. As expected, an increase in given social support led to a greater decrease in job tension for those with older comparative age. 
Social support (traditional/received). Traditional social support, characterized by opportunities to receive social support from others, did not interact with chronological age to predict job satisfaction. The result was the same when using comparative age in place of chronological age. Interestingly, the interaction between social support and chronological age was significant in predicting job tension, but in the opposite direction as hypothesized. An increase in social support led to a greater decrease in job tension for older employees than for younger employees. Although this was not the relationship hypothesized according to SES theory, it makes sense when considered in light of SOC theory: Older adults may need to receive more social support in order to gauge the effectiveness of their compensation strategies. It is also likely that investigation of mediators, such as future time perspective (Zacher \& Frese, 2009), is needed to understand these complex relationships. Future time perspective, which describes how much time individuals believe they have left in their future (and in their careers), relates to perceptions of remaining opportunities at work. Age and work characteristics have been shown to interact to affect these perceptions of future opportunities, which likely affect job satisfaction and job tension. Considering such mediators would help to reveal the mechanisms underlying the relationship between job characteristics and indicators of well being.

When subjective age was used in place of chronological age, an increase in social support led to a decrease in job tension for those with higher comparative age, but did not affect those with lower comparative age. While this goes against my hypothesis, it has 
been proposed that traditional (received) social support should be beneficial to employees throughout the lifespan, as it provides a positive way to cope with difficult work situations (Truxillo, Cadiz, Rineer, Zaniboni, \& Fraccaroli, under review). Furthermore, these findings provide additional evidence that given and received social support should be considered as different job characteristics.

Interdependence. I did not have a hypothesis for how interdependence would interact with age to affect job satisfaction and job tension. Results showed that not only were the interactions between interdependence and age not significant, but that the main effect of interdependence did not significantly predict job satisfaction or job tension. This is not totally surprising considering how interdependence was measured in this study. Interdependence is said to create a more complex and potentially motivating job because it requires increased interactions with coworkers in order for work to be completed (Kiggundu, 1983). However, the items assessing interdependence in the WDQ, such as "The job requires me to accomplish my job before others complete their job", and "My job depends on the work of many different people for its completion" are neutrally worded. This can be contrasted to, say, an item assessing social support that is clearly positively valenced: "People I work with are friendly." Thus, it is easy to imagine that interdependence is neither inherently good nor bad; rather, the extent to which employees prefer interdependence may largely rely on the quality of the relationships they have with their colleagues, which is not measured with the WDQ items. Rather, although 
interdependence may be a job characteristic that differentiates jobs, its effects on worker attitudes and perceptions may be minimal.

Interaction outside the organization. Regarding interaction outside the organization, only the interaction between interaction outside the organization and subjective age was significant in predicting an outcome: job satisfaction. This interaction was in the predicted direction; an increase in interaction outside the organization led to an increase in job satisfaction for those with younger comparative age, but a decrease in job satisfaction for those with older comparative age. This is in line with previous research on this job characteristic and age: Zaniboni et al. (2011) found that interaction outside the organization led to more positive outcomes for younger workers. These findings are supported by SES theory, which suggests that younger workers, because of their more future oriented time perspective, place greater priority on seeking knowledge from social relationships (Carstensen et al., 1999). Increased external interactions increase access to a broader range of social partners, which fulfills the desire to invest in a broad range of relationships to gather information. In contrast, older workers have less desire to have a broad range of relationships and would rather focus their priorities on strengthening existing relationships. The interaction between interaction outside the organization and age was not significant when using chronological age, nor in predicting job tension, however. This may be due to statistical power issues and a relatively small sample size.

Feedback from others. The interaction between feedback from others and age significantly predicted job satisfaction when chronological age was used. As 
hypothesized, an increase in feedback had virtually no effect on job satisfaction for older employees, but led to an increase in job satisfaction for younger employees. A similar result was found when comparative age was used; however, the interaction was only marginally significant. These findings make intuitive sense: Feedback from others is likely to be especially important to younger workers because they are in the beginning stages of their careers and need such feedback for growth and development. However, the interaction between feedback from others and age was not significant in predicting job tension (using either chronological age or subjective age). These results are in line with the earlier work of Herzberg (1966), who proposed that the factors that lead to job satisfaction are different from the factors that lead to job dissatisfaction (or in this case, job tension).

Social support characteristics and theory. While overall, only about half of the hypotheses were supported (and half of the research question interactions found to be significant), it appears that the theoretical rational, based in SES theory, is still sound. It does appear, however, that instead of there being a differentiation between preferences for given and received social support for workers of different ages, older workers simply prefer more social support in general. This is, in fact, aligned with SES theory (Carstensen et al., 1999), which would predict that older workers prefer jobs that are more relational, and thus more emotionally fulfilling. The other cases of unsupported hypotheses are likely due to statistical power issues or the way items are phrased in the WDQ. 


\section{Comparative Age}

One of the unique components of this study was the incorporation of a subjective age measure in evaluating the relationship between job design characteristics, age, and outcomes. Although this study provides some evidence for the utility of subjective age in predicting important organizational outcomes, the high correlation between chronological age and comparative age suggests that what the two constructs measure may be essentially the same. In the future, it may be beneficial to use additional measures of subjective age that are more conceptually distinct from chronological age. This may provide greater insight into the experience of older workers. For example, Barnes-Farrell, Rumery, and Swody (2002) found that Feel-Old (the extent to which a worker reports feeling older than his/her chronological age) was the single psychological age variable (among Feel-Old, Look-Old [the extent to which a worker reports that he/she looks older than his/her chronological age], Act-Old [the extent to which a worker reports that he/she acts older than his/her chronological age], and Prefer-Old [the extent to which a worker's preferred age is older than his/her chronological age) that was most consistently related to measures of work strains and work outcomes. It may be that a positive difference in FeelOld (indicating that the respondent feels older than his/her chronological age) would moderate the relationships between job design characteristics and job satisfaction and job tension as hypothesized in this study to a greater extent than chronological or comparative age. The theories used in this study emphasize the importance of perceptions of time remaining and compensation strategies that are needed as one's needs and 
abilities change throughout the lifespan. It makes sense to think, then, that the relationships proposed in this study may depend more on how old a person feels than how old they actually are or how old they are relative to others.

\section{Implications for Practice}

Research on how to attract and retain older workers is particularly relevant and has practical value at this point in history as the industrialized workforce continues to age. Some companies are already taking strides to adapt their practices to support older workers. Scripps Health, for example, which was recently named the Best Employer for Workers over 50 by AARP (formerly the American Association of Retired Persons), uses senior placement agencies to target mature workers and retirees. Relevant to the current study, they also employ a Clinical Mentorship Program, which gives highly skilled clinicians the opportunity to serve as role models and teachers (provide social support) within each patient care unit (AARP, 2011). As the literature in this area continues to develop, it will be possible to make further recommendations to employers regarding how to best support their aging workers, in turn, improving both the experiences of workers of all ages as well as overall organizational effectiveness.

It may also be beneficial for employers to support job crafting among older workers. Wrzesniewski and Dutton (2001) describe job crafting as the process through which employees proactively alter the boundaries of their own tasks and relationships at work. More specifically, employees can change physical task boundaries by altering the number or type of 
tasks that they complete, cognitive task boundaries by reframing their views of their tasks, and relational boundaries by altering with whom and how they interact and communicate at work. Older employees in particular have acquired the knowledge and skills needed to redesign their jobs to fit their needs and abilities. This may be one of the most practical recommendations that can be made to organizations at this point. Although research on job design and aging has gained momentum in recent years, it is still (in many ways) too early to make general conclusions about what is most beneficial for younger versus older employees. However, job crafting allows each employee to reflect on their own individual strengths and challenges and redesign the job to increase their productivity and satisfaction throughout the aging process. (At the same time, it is important to note that different jobs and industries may vary in the extent to which job crafting is possible. For example, a college professor is more likely to have the autonomy and flexibility to adapt their roles than an assembly line worker. These contextual constraints would need to be considered before suggesting job crafting as a workplace intervention.)

\section{Potential Limitations}

As with all empirical research, this study is not without its limitations. First, the nature of the data is cross-sectional. As such, it is difficult to determine causality of effects. However, since the main focus of this study was on interactions - demonstrating that relationships between antecedents and outcomes differ depending on a third variable - the disadvantageous nature of using cross-sectional data is mitigated to some degree. 
Second, the study is susceptible to issues related to common method variance, as all data are self-report. However, one of the primary variables, chronological age, is less susceptible to effects of self-report. Additionally, while the overall gender breakdown of the sample is known, gender was not collected in the demographic section of the questionnaire. Thus, it could not be included in analyses. As gender may be a useful control variable, it should be included in future studies. Another issue with the current study is the fact that the sample used was relatively small, making detection of interactions difficult. Lastly, the length of the survey administered warrants some concern about participant fatigue. It is important to note, however, that all scales that were not deemed completely necessary were removed from the final version of the survey.

\section{Implications for Future Research}

Because there is little extant research on the interaction between age and job design, there are many important avenues for future research. For example, contextual factors of the workplace should be taken into account. Specifically, age stereotypes and age diversity climate (Cadiz, 2011) may impact older workers' perceptions of their jobs. In addition, additional job design factors, such task and knowledge characteristics, should be investigated in terms of their effect on older versus younger workers. Further, the role of other individual difference moderators (in addition to age), such as knowledge, skills, abilities, personality, and interests should be examined (Grant, Fried, \& Juillerat, 2010). This will help provide a more complete picture of the types of job design that support older workers and the mechanisms in that relationship. 
Also, it is important to note that comparative age may differ in utility based on the context in which it is measured, and may depend on the age range of the employees in a given workplace. Future studies should also utilize other constructs of subjective age that may be conceptually more distinct from chronological age than comparative age. Measures of Feel Age (Barnes-Farrell, Rumery, and Swody, 2002), for example, may provide more useful in addressing the complexity of age in the workplace.

Additionally, it is important that future research be conducted in different contexts, and with different types of jobs (and also with larger samples, to aid in the detection of moderated relationships). These different environments could act as boundary conditions for the mechanisms proposed in the current study. Further experiments should include both white and blue collar workers, employees in different cultures, and a wide range of organizational settings (including private and non-profit organizations, as well as public organizations, such as the Water Bureau.) Replicating this type of study in varying contexts will allow researchers to understand the extent to which these results are generalizable, and the conditions in which the relationships between variables change. Along the same lines, there may be differential rates of participation and/or critical differences between employees according to job type or department. To address this, future research should consider controlling for these factors. Also, there may be a difference in how supervisors and non-supervisors experience various work characteristics. Future studies could benefit from examining these relationships amongst non-supervisory employees only. It is important to note, however, 
that social desirability effects may come into play in responses for non-supervisory employees in particular, especially for characteristics like given social support (which employees may feel the need to respond positively to).

Future studies are also needed to investigate the role of person-environment fit in the relationship between job design characteristics and outcomes. It may be that the mechanism through which job design affects outcomes like job satisfaction and job tension is the extent to which an employee perceives that the environmental demands of their job match their abilities and preferences. Research suggests that older workers examine whether the degree of fit between their current positions and their skills and interests has decreased over time (Feldman \& Beehr, 2011). Because jobs and organizations often change significantly over the course of three or four decades (or the amount of time people generally spend in the work force), older workers sometimes find themselves in jobs they no longer find rewarding. Further, even if the work environment itself does not change much over time, individuals' capacity for dealing with their environments may do so. The more that older workers perceive declining fit, the more likely it is they will experience decreased satisfaction and increased tension. Thus, considering person-environment fit as a mediator would likely enhance our understanding of the processes involved in employees' responses to their job characteristics. Further, Perry, Dokko, and Golom (2012) discuss the need to not only investigate general personenvironment fit, but also the more specific concepts of person-job fit (match between an individual's knowledge, skills, and abilities [KSAs] and those required by a particular 
job; Kristof-Brown et al., 2005); person-person fit (the extent to which there is fit in the dyadic relationships formed with others at work); person-group fit (the compatibility between individuals and their work groups on interpersonally relevant dimensions; Jansen \& Kristof-Brown, 2006); and person-organization fit (fit between an individual and an employing organization), in assessing the relationship between age and outcomes such as job satisfaction and intentions to quit.

Other mediators that should be considered in future research in the relationship between job characteristics and job satisfaction and job tension include perceived time remaining (Carstensen, 2006) and perceived opportunities (Zacher \& Frese, 2009). Perceived time remaining, or future time perspective, describes how much time individuals believe they have left in their future, and how they perceive that time. Zacher and Frese (2009) have shown that age is negatively related to both future time perspective and remaining opportunities at work. However, they found that work characteristics moderate the relationship between age and remaining opportunities, such that the relationship is weaker with increasing levels of job complexity and control. Future studies would benefit from including these variables of future time perspective and perceived opportunities in theoretical models. It is possible, for example, that social support could weaken the negative relationship between age and remaining opportunities, as older adults may have access to a greater number and variety of resources (which could lead to work opportunities) through their social networks.

A final set of mediators that may provide utility in understanding the relationships examined in this study is the critical psychological states of experienced meaningfulness, 
responsibility, and knowledge of results, as proposed by Hackman and Oldham (1975). The authors purport that job design characteristics affect individual and work outcomes (such as job satisfaction) through their effects on these three psychological states. Experienced meaningfulness refers to the degree to which the employee experiences the job as one which is generally meaningful, valuable, and worthwhile; responsibility refers to the degree to which the employee feels personally accountable and responsible for the results of the work he or she does; and knowledge of results is defined as the degree to which the employee knows and understands, on a continuous basis, how effectively he or she is performing the job. One can imagine, for instance, that given social support, or the opportunity to provide social support to others, may increase experienced meaningfulness of the work. Similarly, the social support characteristic of interdependence may lead to increased perceptions of responsibility. Lastly, feedback from others is likely related to knowledge of results. Future studies should consider these psychological states as mediators, in order to help explain the pathways through which job design characteristics affect individual outcomes for employees throughout the lifespan.

A proposed model for future research, which includes the potential mediators of person-environment fit, perceived time remaining, perceived opportunities, and critical psychological states, is in Figure 10. Examination of such mediators may be the key to understanding the mechanisms underlying the relationship between social job characteristics and indicators of work-related wellbeing, as moderated by age. Future studies examining the role of these variables would help to explain why some interactions in the current study were in the opposite direction of what was hypothesized based on 
Socioemotional Selectivity Theory. This integrative model should be utilized by researchers aiming to shed light on the "black box" of mechanisms leading to differential outcomes in response to the same job characteristics.

Another area for future research regards utilizing a more nuanced view of the social job design characteristics. For example, the items measuring feedback from others in the WDQ are neutrally worded and do not take into account valence of feedback. Yet, research has shown that positive and negative feedback lead to positive and negative affect, respectively, which then has differential effects on work attitudes and behaviors, including organizational citizenship behaviors, organizational commitment, and turnover intentions (Belschak \& Den Hartog, 2009). The general description of feedback used in the WDQ may prevent a clear understanding of the effects of feedback on worker attitudes. Similar issues relate to the neutrally-worded items regarding interdependence. A different measure of interdependence (that includes quality of work relationships or team climate) may provide a better understanding of the effects of interdependence on job satisfaction and job tension. Future studies should consider the possibility of 3-way interaction between, for example, interdependence, team climate, and age.

Relatedly, there are a number of additional factors beyond age that likely come into play to explain the relationships between social job design characteristics and outcomes such as job satisfaction and job tension. Within younger workers and within older workers, there is likely to be variability on a number of factors, including personality, which may influence job design preferences. For instance, extraversion (in 
particular, the facet of gregariousness), will likely lead to greater satisfaction with the social characteristics of interaction outside the organization and social support for workers of all ages. In other words, a range of additional moderators are likely at play, and these should be examined in future research of the interaction between age and job characteristics.

Longitudinal studies examining changes in people's job design preferences over time would also be highly beneficial. According to Fried, Grant, Levi, Hadani, and Haynes Slowik (2007), the failure to include time in job design theory can prevent a theory's ability to accurately predict individual attitudes and behaviors in organizations, which are influenced by events that have happened in the past, are presently occurring, and may occur in the future. Lastly, future research should examine non-linear relationships between age and job design outcomes. Previous research has shown a curvilinear relationship between age and performance. For example, $\mathrm{Ng}$ and Feldman (2008) found that the relationships between age and core task performance for four age groups-under 30 years old, 31-35, 36-40, and over 40 years old-were .04, .09, .06, and -.05, respectively. Thus, they explained that there seems to be an inverted-U shape relationship between age and task performance for people in different age groups. They concluded that the relationship between age and performance is strongest and most positive for 31-35 year-olds but weaker for workers under 30 and negative for workers over 40. Taking these types of nonlinear aging relationship into account will help provide a better understanding of the effects of job design characteristics throughout the lifespan. 


\section{Conclusion}

As the workforce continues to age, research on age and job design will become increasingly important in Industrial/Organizational Psychology. This study is a critical first step of a program of research that will help match workers' resources with the demands of their jobs. This study responded to the call (e.g., Grant, Fried, \& Juillerat, 2010) for the examination of moderators in the relationship between job design

characteristics and individual outcomes, and challenges the "one size fits all" approach to job design (e.g., Morgeson \& Humphrey, 2006). Specifically, Morgeson and Humphrey previously stated that "the relationships between the work design characteristics and outcomes tend to be in the same direction for all employees, even if they differ in strength between employees" (Morgeson \& Humphrey, 2006, p. 1334). Thus, the present study demonstrates a possible moderator of the effects of job characteristics - age - and integrates job design (an I/O psychology topic) with SES theory (a theory arising from the developmental psychology literature).

In this study, a number of interactions were found to be significant, helping to increase understanding of how younger and older workers are differentially affected by the same job characteristics. Further, the present study helped to integrate job design and lifespan development theories. Additionally, the use of job tension and job satisfaction as outcomes helps to further differentiate the two theoretical constructs. Not only did the outcomes appear to be distinct in factor analyses, they were also differentially predicted by the independent variables used in this study. Lastly, the new measure of given social 
support leads to a more nuanced understanding of the social support construct. This new measure can subsequently be used to better understand the antecedents and outcomes of different types of social support in future studies.

As the age diversity of the workforce increases, new issues arise that can hinder the productivity and morale of organizations. Unfortunately, discriminatory practices against older workers are not uncommon (Malinen, 2009). This is likely in part due to the fact that companies have not yet learned how to capitalize on the strengths and experiences of older workers, and thus only focus on declines in performance. Moreover, research is only beginning to examine how to keep workers engaged and productive across the lifespan. Ultimately, the results of this study will support employees throughout the lifespan, increase the effectiveness of organizations, and provide a useful basis for understanding how older and younger workers are differentially affected by the characteristics of their jobs. 
Table 1

Means, Standard Deviations, and Intercorrelations among Study Variables

\begin{tabular}{|c|c|c|c|c|c|c|c|c|c|c|c|c|c|c|c|c|}
\hline Variable & $\mathrm{M}$ & $\mathrm{SD}$ & 1 & 2 & 3 & 4 & 5 & 6 & 7 & 8 & 9 & 10 & 11 & 12 & 13 & 14 \\
\hline 1. Age & 48.74 & 9.80 & & & & & & & & & & & & & & \\
\hline 2. Comparative Age & 3.19 & .95 & $.83^{* *}$ & & & & & & & & & & & & & \\
\hline 3. Job Tenure & 11.57 & 8.02 & $.44^{* *}$ & $.34^{* *}$ & & & & & & & & & & & & \\
\hline 4. Supervisory Status & 1.55 & .50 & $.24^{* *}$ & $.30^{* *}$ & $.27^{* *}$ & & & & & & & & & & & \\
\hline 5. Income level & 5.51 & 1.47 & $.16^{*}$ & $.28^{* *}$ & $.18^{\star}$ & $.61^{* *}$ & & & & & & & & & & \\
\hline 6. Union & 1.62 & .49 & .11 & .13 & $.19^{*}$ & $.76^{* *}$ & $.55^{* *}$ & & & & & & & & & \\
\hline 7. Education Level & 3.87 & .81 & .03 & .04 & $-.16^{*}$ & $.36^{* *}$ & $.24^{* *}$ & $.37^{* *}$ & & & & & & & & \\
\hline 8. SS Given & 4.04 & .64 & .03 & -.04 & $.21^{* *}$ & $.18^{*}$ & $.19^{*}$ & $.25^{* *}$ & .12 & $(.91)$ & & & & & & \\
\hline 9. SS & 3.74 & .53 & -.07 & -.05 & .09 & .06 & .11 & $.16^{*}$ & $.17^{*}$ & $.60^{* *}$ & $(.77)$ & & & & & \\
\hline 10. Interdependence & 3.70 & .60 & -.08 & -.11 & .04 & .05 & .03 & .03 & .10 & $.31^{* *}$ & $.16^{*}$ & $(.81)$ & & & & \\
\hline 11. Interaction & 3.26 & .91 & $.23^{* *}$ & $.20^{* *}$ & $.16^{*}$ & -.10 & -.05 & -.10 & -.13 & .00 & .03 & .12 & $(.90)$ & & & \\
\hline 12. Feedback & 3.03 & .86 & -.01 & -.02 & -.01 & -.13 & $.23^{-}$ & -.12 & .09 & .08 & $.27^{* *}$ & .13 & .13 & $(.88)$ & & \\
\hline 13. Job Satisfaction & 3.65 & .75 & .04 & .03 & $.26^{* *}$ & $.26^{* *}$ & $.24^{* *}$ & $.28^{* *}$ & .09 & $.57^{* *}$ & $.58^{* *}$ & .10 & .02 & $.21^{\star *}$ & $(.90)$ & \\
\hline 14. Job Tension & 3.15 & .74 & .14 & .07 & .12 & .00 & .04 & -.07 & $.25^{-* *}$ & $.27^{-}$ & $.36^{* *}$ & $.16^{*}$ & .04 & -.13 & $.33^{* *}$ & $(.84)$ \\
\hline
\end{tabular}

Notes. Cronbach's alpha in parenthesis on the diagonal. Comparative Age measured on a scale from 1-5, with $1=$ much younger than coworkers and $5=$ much older than coworkers. Supervisory Status was coded as $1=$ non-supervisor, $2=$ supervisor. Income Level ranged from $1-7$, with $1<\$ 25,000$ and $7>\$ 100,000$. Union was coded as $1=$ union member, $2=$ non-union. Education level measured on a scale from 1-5, with $1=$ some high school and $5=$ graduate degree.

SSGiven $=$ Given Social Support. SS $=$ Social Support. Social job characteristics were measured on a scale from 1-5, with $1=$ strongly disagree, $5=$ strongly agree

$* \mathrm{p}<.05 ; * * \mathrm{p}<.01, N=186$ 
Table 2

Summary of Interaction Hypothesis Results of Effects of Social Job Characteristics and Age on Job Satisfaction and Job Tension.

\begin{tabular}{lcccc}
\hline & \multicolumn{2}{c}{ Job Satisfaction } & \multicolumn{2}{c}{ Job Tension } \\
\cline { 2 - 5 } Social Job Characteristic & Chronological & Subjective & Chronological & Subjective \\
& Age & Age & Age & Age \\
Given Social Support & $\dagger$ & N & Y & Y \\
Social Support & $\mathbf{N}$ & $\mathrm{N}$ & $\mathbf{Y}$ & $\mathrm{Y}$ \\
Interdependence & $\mathrm{N}$ & $\mathrm{N}$ & $\mathrm{N}$ & $\mathrm{N}$ \\
Interaction Outside the Organization & $\mathbf{N}$ & $\mathrm{Y}$ & $\mathbf{N}$ & $\mathrm{N}$ \\
Feedback from Others & $\mathbf{Y}$ & $\dagger$ & $\mathbf{N}$ & $\mathrm{N}$ \\
\hline
\end{tabular}

Notes.

$\dagger$ denotes that the interaction between the social job characteristic and age was marginally significant in predicting the outcome (either job satisfaction or job tension).

$\mathrm{Y}$ signifies that the interaction relationship was significant in predicting the outcome; $\mathrm{N}$ signifies that the relationship was not significant.

Hypotheses are in bold, while research questions are in plain text.

$N=186$ 
Table 3

Hierarchical Multiple Regression Analyses Predicting Job Satisfaction and Job Tension from Given Social Support and Age (Chronological and Subjective)

\begin{tabular}{|c|c|c|c|c|c|c|c|c|c|c|c|c|}
\hline \multirow[b]{3}{*}{ Predictor } & \multicolumn{6}{|c|}{$\underline{\text { Sob }} \underline{\underline{\text { Satisfaction }}}$} & \multicolumn{6}{|c|}{$\underline{\text { Job Tension }}$} \\
\hline & \multicolumn{3}{|c|}{ Chronological Age } & \multicolumn{3}{|c|}{$\underline{\text { Subjective Age }}$} & \multicolumn{3}{|c|}{ Chronological Age } & \multicolumn{3}{|c|}{ Subjective Age } \\
\hline & $\beta$ & $\Delta R^{2}$ & $R^{2}$ & $\beta$ & $\Delta R^{2}$ & $R^{2}$ & $\beta$ & $\Delta R^{2}$ & $R^{2}$ & $\beta$ & $\Delta R^{2}$ & $R^{2}$ \\
\hline Step 1 & & $.14 *$ & .14 & & $.14 *$ & .14 & & $.08^{*}$ & .08 & & $.08 *$ & .08 \\
\hline Education Level & .01 & & & -.01 & & & $-.19 *$ & & & $-.18 *$ & & \\
\hline Job Tenure & .01 & & & .01 & & & .01 & & & .01 & & \\
\hline Income Level & .03 & & & .04 & & & .06 & & & .06 & & \\
\hline Union & .07 & & & .09 & & & -.10 & & & -.14 & & \\
\hline Supervisory Status & .12 & & & .06 & & & .17 & & & .24 & & \\
\hline Step 2 & & $.21 *$ & .35 & & $.21 *$ & .35 & & $.04 *$ & .12 & & $.04 *$ & .12 \\
\hline Given Social Support & $.32 *$ & & & $.35^{*}$ & & & $-.20 *$ & & & $-.20^{*}$ & & \\
\hline Step 3 & & .00 & .35 & & .00 & .36 & & .00 & .12 & & .00 & .13 \\
\hline Age & -.05 & & & .01 & & & .02 & & & -.07 & & \\
\hline Step 4 & & $.01 \dagger$ & .36 & & .00 & .36 & & $.05^{*}$ & .17 & & $.10 *$ & .22 \\
\hline $\begin{array}{l}\text { Given Social Support* } \\
\text { Age }\end{array}$ & $-.08 \dagger$ & & & -.02 & & & $-.15^{*}$ & & & $-.23^{*}$ & & \\
\hline
\end{tabular}

Note. Values reported are for the final equation.

$* p<.05, \dagger$ denotes marginal significance $(p<.10)$

$N=186$ 
Table 4

Hierarchical Multiple Regression Analyses Predicting Job Satisfaction and Job Tension from Social Support and Age (Chronological and Subjective)

\begin{tabular}{|c|c|c|c|c|c|c|c|c|c|c|c|c|}
\hline \multirow[b]{3}{*}{ Predictor } & \multicolumn{6}{|c|}{ Job Satisfaction } & \multicolumn{6}{|c|}{ Job Tension } \\
\hline & \multicolumn{3}{|c|}{ Chronological Age } & \multicolumn{3}{|c|}{$\underline{\text { Subjective Age }}$} & \multicolumn{3}{|c|}{ Chronological Age } & \multicolumn{3}{|c|}{$\underline{\text { Subjective Age }}$} \\
\hline & $\beta$ & $\Delta R^{2}$ & $R^{2}$ & $\beta$ & $\Delta R^{2}$ & $R^{2}$ & $\beta$ & $\Delta R^{2}$ & $R^{2}$ & $\beta$ & $\Delta R^{2}$ & $R^{2}$ \\
\hline Step 1 & & $.14^{*}$ & .14 & & $.14^{*}$ & .14 & & $.08^{*}$ & .08 & & $.08 *$ & .08 \\
\hline Education Level & -.07 & & & -.06 & & & -.13 & & & $-.16^{*}$ & & \\
\hline Job Tenure & $.01 \dagger$ & & & $.01 \dagger$ & & & .01 & & & $.01 \dagger$ & & \\
\hline Income Level & .04 & & & .05 & & & .07 & & & $.08 \dagger$ & & \\
\hline Union & .08 & & & .10 & & & -.15 & & & -.16 & & \\
\hline Supervisory Status & .17 & & & .12 & & & .15 & & & .11 & & \\
\hline Step 2 & & $.22 *$ & .35 & & $.22^{*}$ & .36 & & $.11^{*}$ & .18 & & $.09 *$ & .17 \\
\hline Social Support & $.35^{*}$ & & & $.36^{*}$ & & & $-.30 *$ & & & $-.26^{*}$ & & \\
\hline Step 3 & & .00 & .35 & & .00 & .36 & & .00 & .18 & & .01 & .17 \\
\hline Age & -.01 & & & .00 & & & -.05 & & & -.06 & & \\
\hline Step 4 & & .00 & .35 & & .00 & .36 & & $.06^{*}$ & .24 & & $.05^{*}$ & .22 \\
\hline $\begin{array}{l}\text { Social Support * } \\
\text { Age }\end{array}$ & -.01 & & & .05 & & & $-.20 *$ & & & $-.17 *$ & & \\
\hline
\end{tabular}

Note. Values reported are for the final equation.

$*_{p}<.05, \dagger$ denotes marginal significance $(p<.10)$

$N=183$ 
Table 5

Hierarchical Multiple Regression Analyses Predicting Job Satisfaction and Job Tension from Interdependence and Age (Chronological and Subjective)

\begin{tabular}{|c|c|c|c|c|c|c|c|c|c|c|c|c|}
\hline \multirow[b]{3}{*}{ Predictor } & \multicolumn{6}{|c|}{ Job Satisfaction } & \multicolumn{6}{|c|}{ Job Tension } \\
\hline & \multicolumn{3}{|c|}{ Chronological Age } & \multicolumn{3}{|c|}{ Subjective Age } & \multicolumn{3}{|c|}{ Chronological Age } & \multicolumn{3}{|c|}{ Subjective Age } \\
\hline & $\beta$ & $\Delta R^{2}$ & $R^{2}$ & $\beta$ & $\Delta R^{2}$ & $R^{2}$ & $\beta$ & $\Delta R^{2}$ & $R^{2}$ & $\beta$ & $\Delta R^{2}$ & $R^{2}$ \\
\hline Step 1 & & $.14 *$ & .14 & & $.14^{*}$ & .14 & & $.08 *$ & .08 & & $.08^{*}$ & .08 \\
\hline Education Level & .03 & & & .03 & & & $-.24 *$ & & & $-.22 *$ & & \\
\hline Job Tenure & $.02 *$ & & & $.02 *$ & & & .00 & & & .01 & & \\
\hline Income Level & .07 & & & .07 & & & .06 & & & .06 & & \\
\hline Union & .24 & & & .24 & & & -.17 & & & -.22 & & \\
\hline Supervisory Status & -.02 & & & -.06 & & & .13 & & & .15 & & \\
\hline Step 2 & & .02 & .15 & & $.02 \dagger$ & .15 & & .02 & .09 & & .02 & .09 \\
\hline Interdependence & .08 & & & $.09 \dagger$ & & & .08 & & & .09 & & \\
\hline Step 3 & & .00 & .15 & & .00 & .15 & & .01 & .10 & & .00 & .09 \\
\hline Age & -.04 & & & -.01 & & & .06 & & & -.02 & & \\
\hline Step 4 & & .00 & .15 & & .00 & .15 & & .00 & .10 & & .00 & .09 \\
\hline $\begin{array}{l}\text { Interdependence * } \\
\text { Age }\end{array}$ & .01 & & & .02 & & & -.02 & & & .01 & & \\
\hline
\end{tabular}

Note. Values reported are for the final equation.

$*_{p}<.05, \dagger$ denotes marginal significance $(p<.10)$

$N=182$ 
Table 6

Hierarchical Multiple Regression Analyses Predicting Job Satisfaction and Job Tension from Interaction Outside the Organization and Age (Chronological and Subjective)

\begin{tabular}{|c|c|c|c|c|c|c|c|c|c|c|c|c|}
\hline \multirow[b]{3}{*}{ Predictor } & \multicolumn{6}{|c|}{$\underline{\text { Job }}$} & \multicolumn{6}{|c|}{$\underline{\text { Job Tension }}$} \\
\hline & \multicolumn{3}{|c|}{ Chronological Age } & \multicolumn{3}{|c|}{$\underline{\text { Subjective Age }}$} & \multicolumn{3}{|c|}{$\underline{\text { Chronological Age }}$} & \multicolumn{3}{|c|}{$\underline{\text { Subjective Age }}$} \\
\hline & $\beta$ & $\Delta R^{2}$ & $R^{2}$ & $\beta$ & $\Delta R^{2}$ & $R^{2}$ & $\beta$ & $\Delta R^{2}$ & $R^{2}$ & $\beta$ & $\Delta R^{2}$ & $R^{2}$ \\
\hline Step 1 & & $.14^{*}$ & .14 & & $.14^{*}$ & .14 & & $.08^{*}$ & .08 & & $.08 *$ & .08 \\
\hline Education Level & .07 & & & .09 & & & $-.23 *$ & & & $-.23^{*}$ & & \\
\hline Job Tenure & $.02 *$ & & & $.02 *$ & & & .00 & & & .01 & & \\
\hline Income Level & .07 & & & .08 & & & .06 & & & .07 & & \\
\hline Union & .25 & & & .23 & & & -.20 & & & -.24 & & \\
\hline Supervisory Status & -.02 & & & -.04 & & & .13 & & & .17 & & \\
\hline Step 2 & & .00 & .14 & & .00 & .14 & & .00 & .08 & & .00 & .08 \\
\hline Interaction Outside Org. & .02 & & & .01 & & & -.02 & & & .00 & & \\
\hline Step 3 & & .01 & .15 & & .00 & .14 & & .00 & .08 & & .00 & .08 \\
\hline Age & -.08 & & & -.05 & & & .06 & & & -.03 & & \\
\hline Step 4 & & .01 & .16 & & $.03 *$ & .17 & & .00 & .08 & & .01 & .09 \\
\hline $\begin{array}{l}\text { Interaction Outside * } \\
\text { Age }\end{array}$ & -.07 & & & $-.10 *$ & & & .03 & & & .05 & & \\
\hline
\end{tabular}

Note. Values reported are for the final equation.

$*_{p}<.05, \dagger$ denotes marginal significance $(p<.10)$

$N=183$ 
Table 7

Hierarchical Multiple Regression Analyses Predicting Job Satisfaction and Job Tension from Feedback from Others and Age (Chronological and Subjective)

\begin{tabular}{|c|c|c|c|c|c|c|c|c|c|c|c|c|}
\hline \multirow[b]{3}{*}{ Predictor } & \multicolumn{6}{|c|}{$\begin{array}{c}\text { Job } \\
\text { Satisfaction }\end{array}$} & \multicolumn{6}{|c|}{$\underline{\text { Job Tension }}$} \\
\hline & \multicolumn{3}{|c|}{ Chronological Age } & \multicolumn{3}{|c|}{$\underline{\text { Subjective Age }}$} & \multicolumn{3}{|c|}{ Chronological Age } & \multicolumn{3}{|c|}{$\underline{\text { Subjective Age }}$} \\
\hline & $\beta$ & $\Delta R^{2}$ & $R^{2}$ & $\beta$ & $\Delta R^{2}$ & $R^{2}$ & $\beta$ & $\Delta R^{2}$ & $R^{2}$ & $\beta$ & $\Delta R^{2}$ & $R^{2}$ \\
\hline Step 1 & & $.14 *$ & .14 & & $.14^{*}$ & .14 & & $.08^{*}$ & .08 & & $.08 *$ & .08 \\
\hline Education Level & -.02 & & & .00 & & & $-.21 *$ & & & $-.20 *$ & & . \\
\hline Job Tenure & $.02 *$ & & & $.02 *$ & & & .00 & & & .01 & & \\
\hline Income Level & $.11^{*}$ & & & $.11^{*}$ & & & .06 & & & .06 & & \\
\hline Union & .22 & & & .20 & & & -.20 & & & -.24 & & \\
\hline Supervisory Status & .07 & & & .05 & & & .14 & & & .17 & & \\
\hline Step 2 & & $.06^{*}$ & .20 & & $.06^{*}$ & .20 & & .01 & .08 & & .01 & .08 \\
\hline Feedback from Others & $.15^{*}$ & & & $.16^{*}$ & & & -.06 & & & -.05 & & \\
\hline Step 3 & & .00 & .20 & & .00 & .20 & & .00 & .09 & & .00 & .08 \\
\hline Age & -.03 & & & -.01 & & & .04 & & & -.03 & & \\
\hline Step 4 & & $.03 *$ & .23 & & $.02 \dagger$ & .21 & & .00 & .09 & & .00 & .09 \\
\hline $\begin{array}{l}\text { Feedback from Others * } \\
\text { Age }\end{array}$ & $-.12 *$ & & & $-.10 \dagger$ & & & -.03 & & & -.01 & & \\
\hline
\end{tabular}

Note. Values reported are for the final equation.

$* p<.05, \dagger$ denotes marginal significance $(p<.10)$

$N=183$ 


\begin{tabular}{|c|c|c|}
\hline Social Job Characteristics & & \\
\hline $\begin{array}{l}\text { Given Social Support } \\
\text { Received Social Support }\end{array}$ & & $\begin{array}{l}\text { Well-Being } \\
\text { Outcomes }\end{array}$ \\
\hline $\begin{array}{l}\text { Interdependence } \\
\text { Interaction Outside the }\end{array}$ & 4 & $\begin{array}{l}\text { Job Satisfaction } \\
\text { Job Tension }\end{array}$ \\
\hline Feedback from Others & Age & \\
\hline
\end{tabular}

Figure 1: Model of study variables. Solid lines represent hypothesized relationships. 


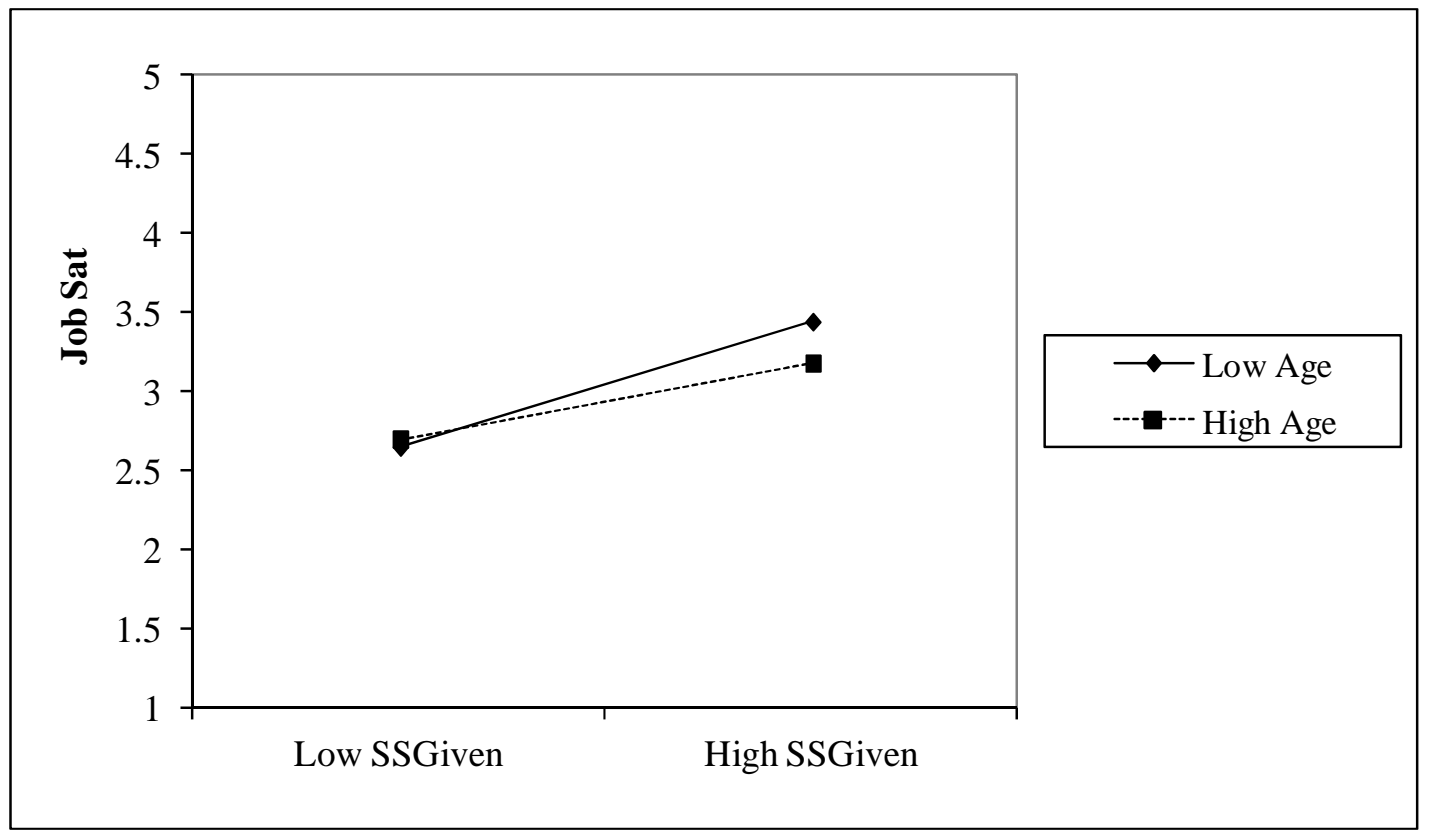

Figure 2. Interaction of given social support and chronological age on job satisfaction.

Note. "Low Age" = 1 standard deviation above the mean = 58.54. "High Age" $=1$ standard deviation below the mean $=38.94$. 


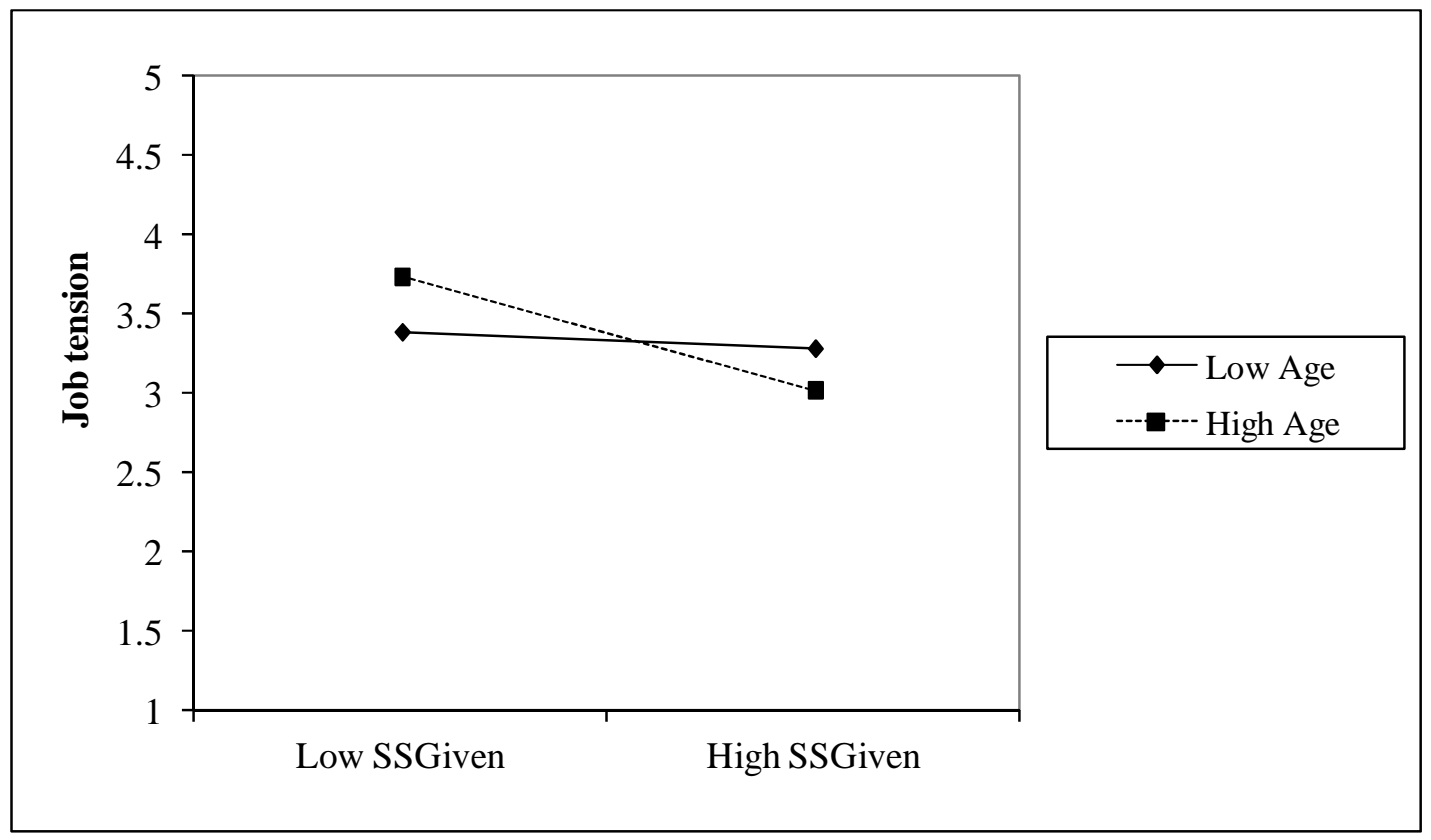

Figure 3. Interaction of given social support and chronological age on job tension.

Note. "Low Age" $=1$ standard deviation above the mean = 58.54. "High Age" $=1$ standard deviation below the mean $=38.94$. 


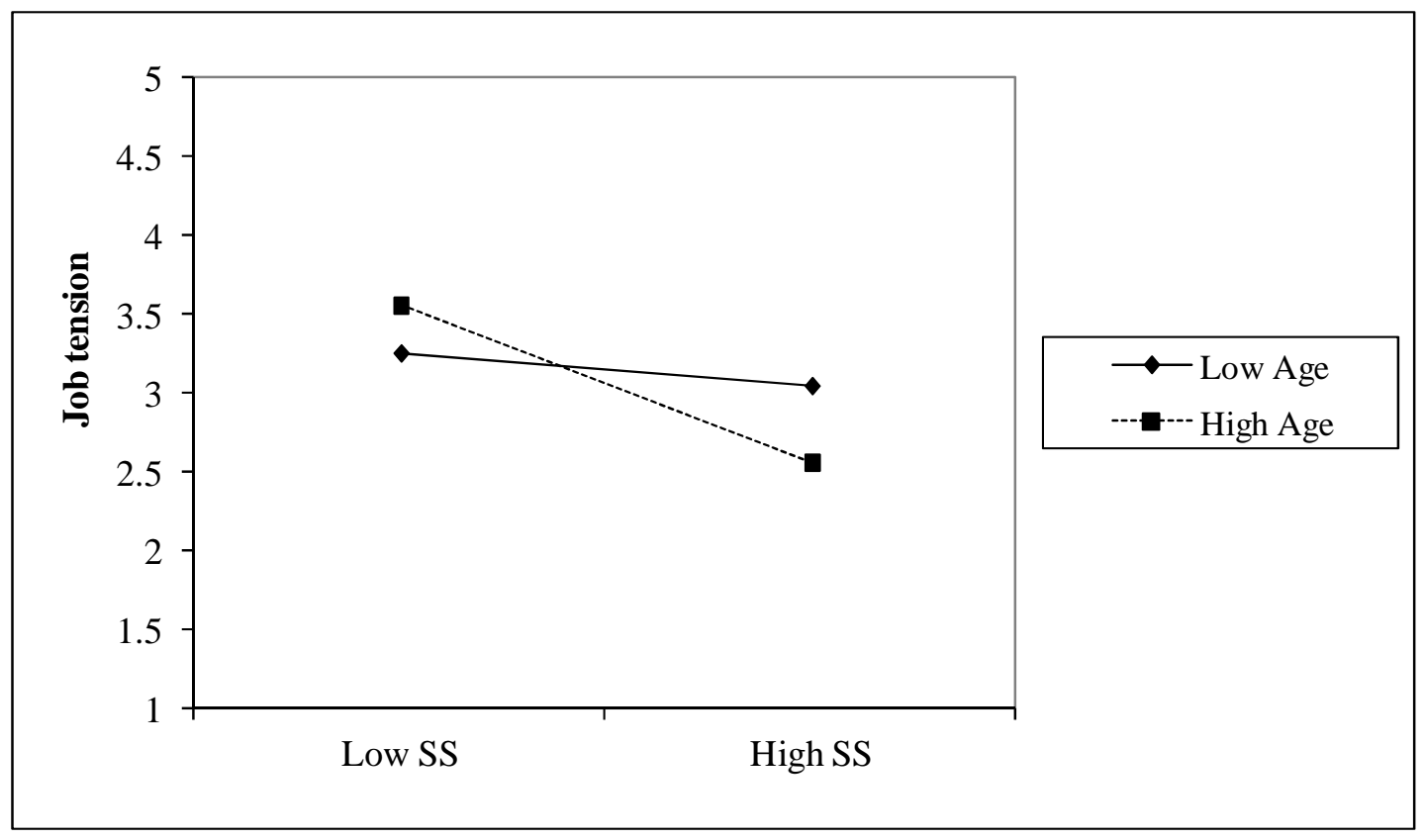

Figure 4. Interaction of social support and chronological age on job tension.

Note. "Low Age" $=1$ standard deviation above the mean $=58.54$. "High Age" $=1$ standard deviation below the mean $=38.94$. 


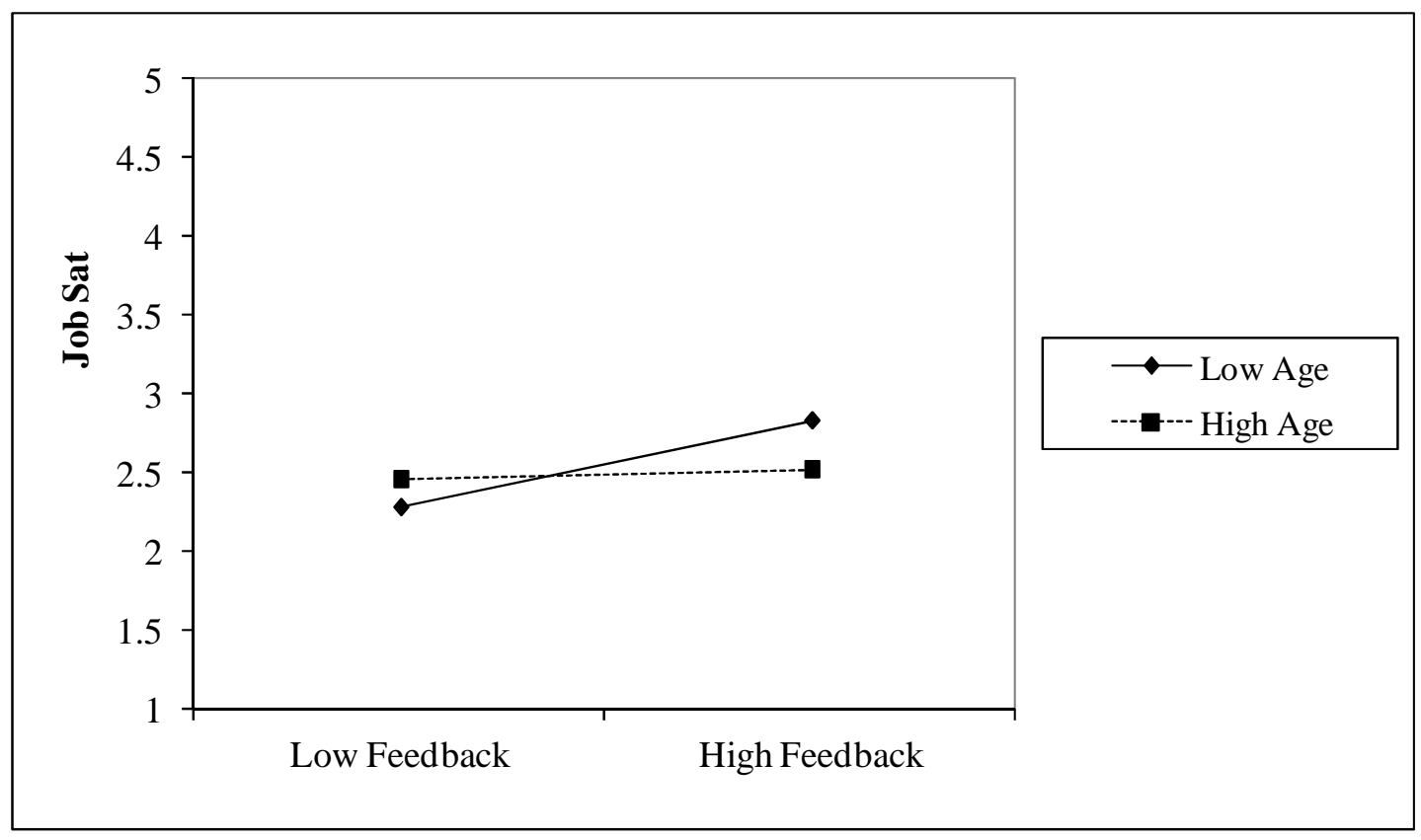

Figure 5. Interaction of feedback from others and chronological age on job satisfaction.

Note. "Low Age" $=1$ standard deviation above the mean $=58.54$. "High Age" $=1$ standard deviation below the mean $=38.94$. 


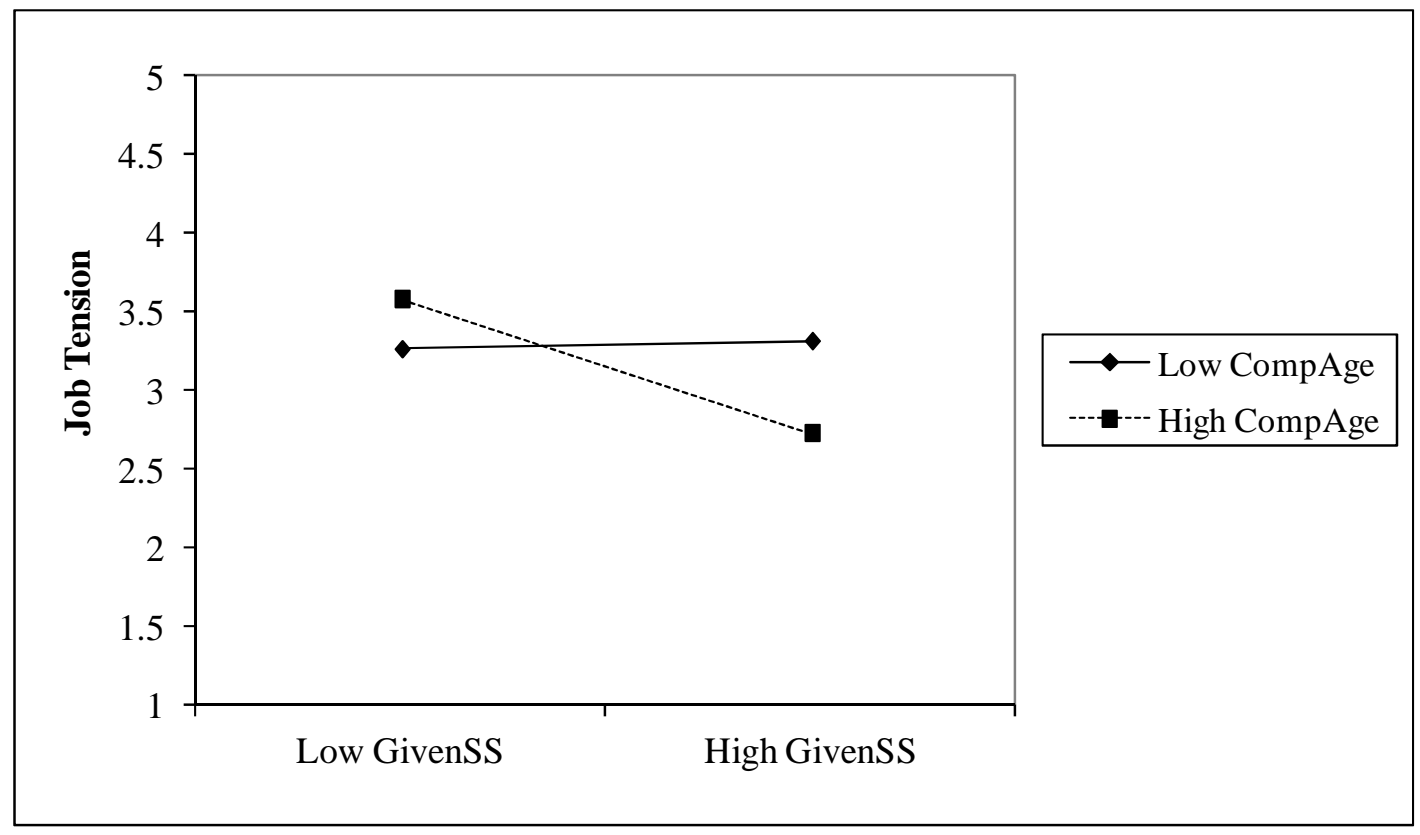

Figure 6. Interaction of given social support and comparative age on job tension.

Note. "Low CompAge" = low comparative age $=4.14$ on a 5-point scale. (4 indicates feeling "older" than one's coworkers.) "High CompAge" = high comparative age $=2.24$ on a 5-point scale. (2 indicates feeling "younger" than one's coworkers.) 


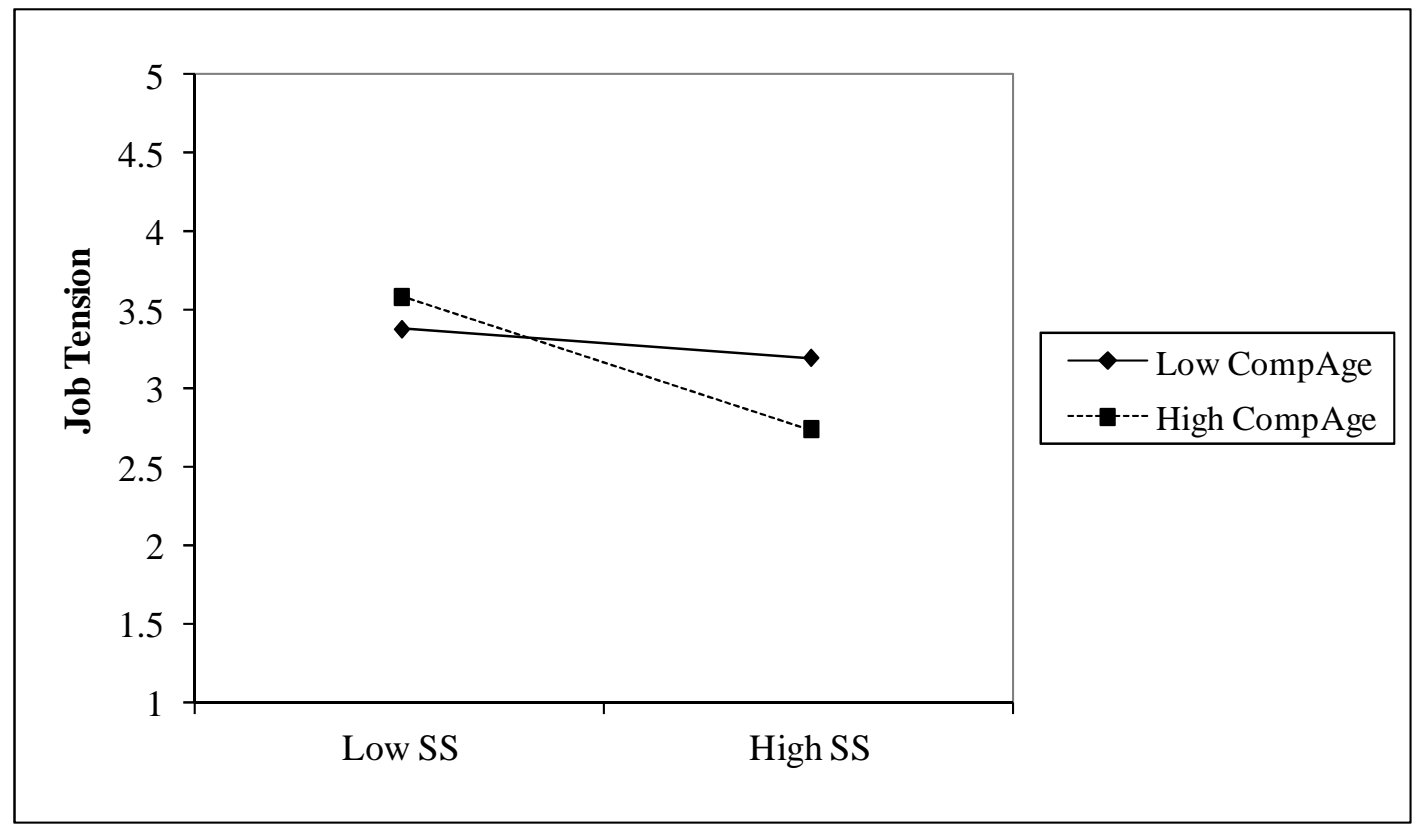

Figure 7. Interaction of social support and comparative age on job tension.

Note. "Low CompAge" $=$ low comparative age $=4.14$ on a 5 -point scale. (4 indicates feeling "older" than one's coworkers.) "High CompAge" = high comparative age = 2.24 on a 5-point scale. ( 2 indicates feeling "younger" than one's coworkers.) 


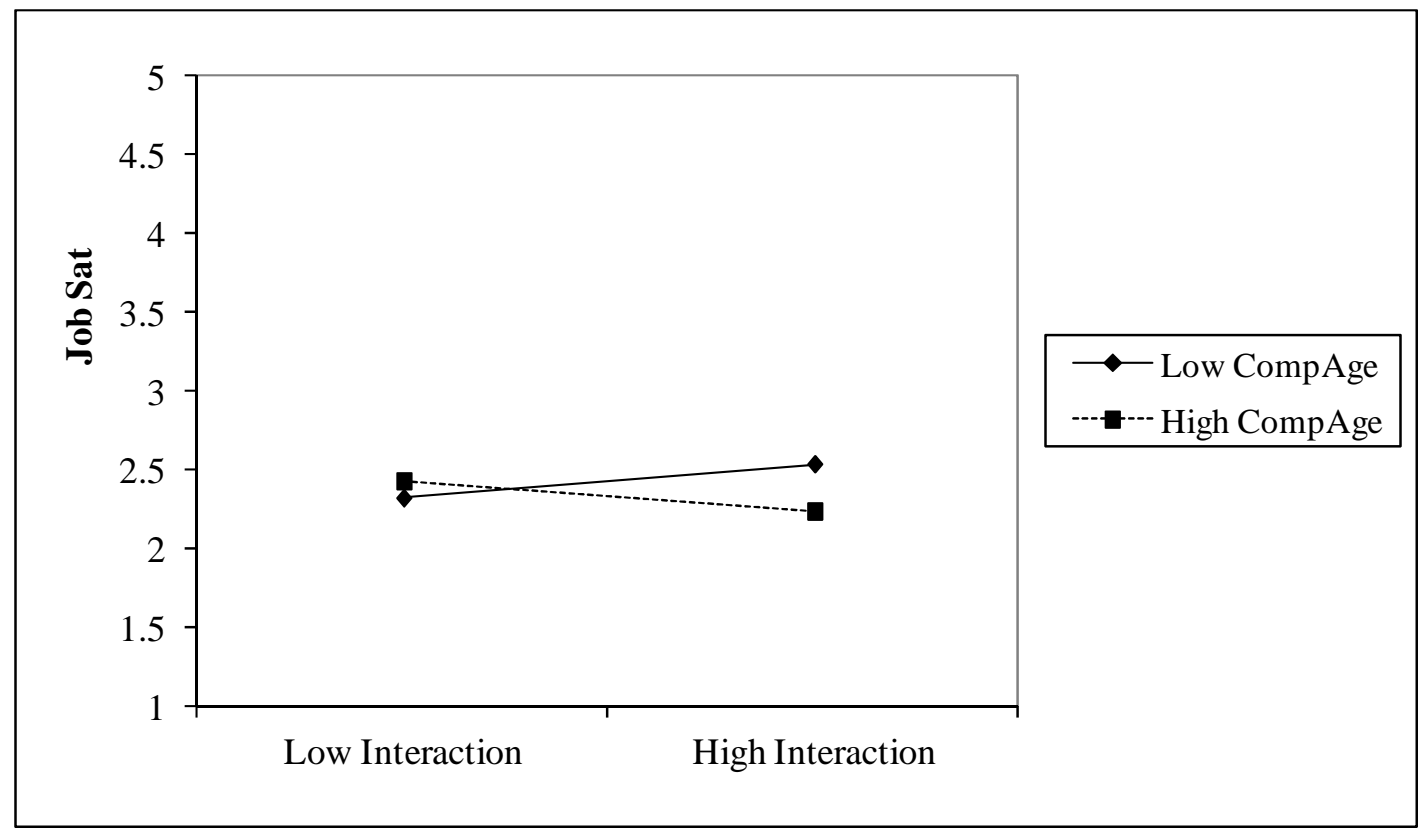

Figure 8. Interaction between interaction outside the organization and comparative age on job satisfaction.

Note. "Low CompAge" = low comparative age $=4.14$ on a 5-point scale. (4 indicates feeling "older" than one's coworkers.) "High CompAge" = high comparative age $=2.24$ on a 5-point scale. (2 indicates feeling "younger" than one's coworkers.) 


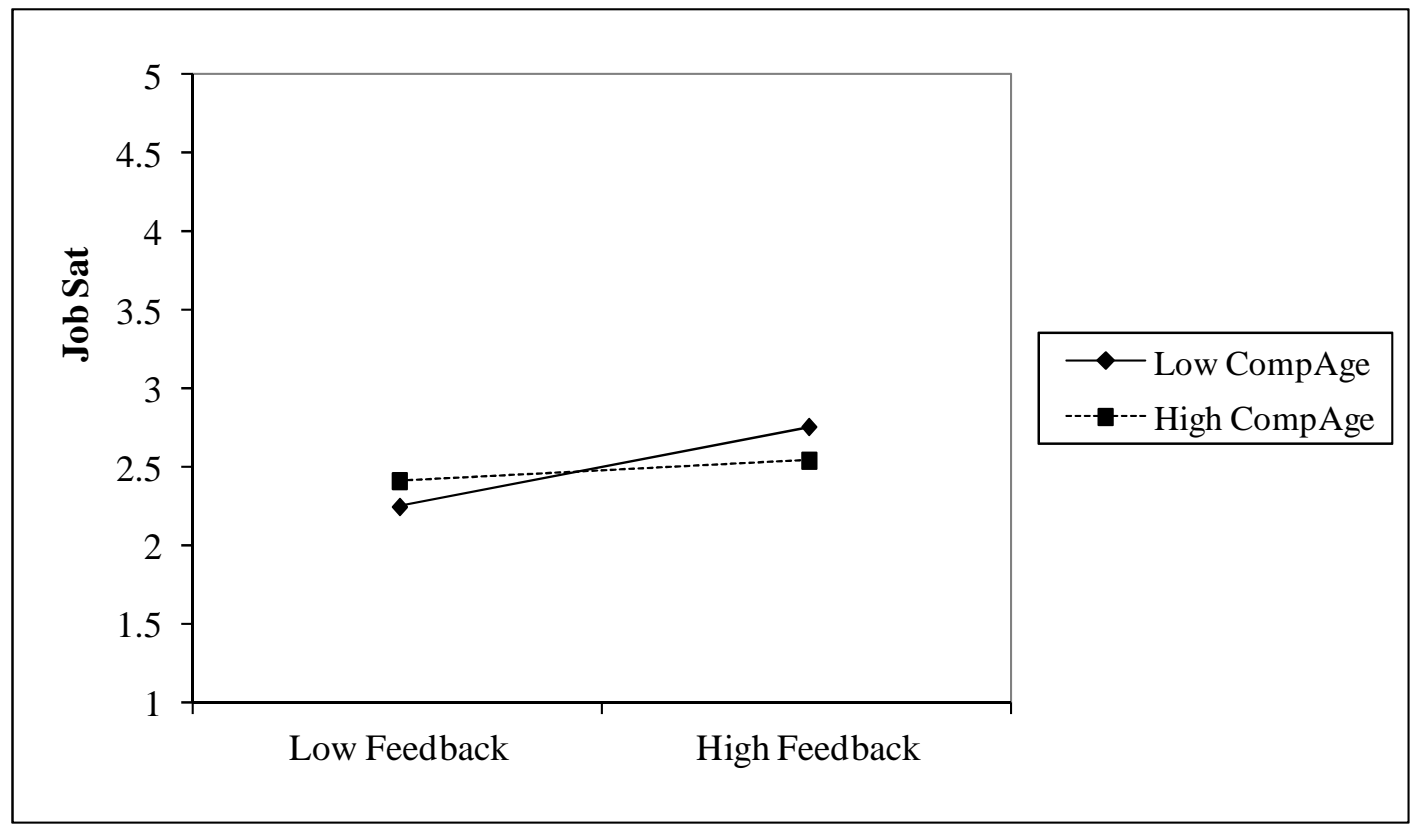

Figure 9. Interaction between feedback from others and comparative age on job satisfaction.

Note. "Low CompAge" = low comparative age $=4.14$ on a 5-point scale. (4 indicates feeling "older" than one's coworkers.) "High CompAge" = high comparative age $=2.24$ on a 5-point scale. ( 2 indicates feeling "younger" than one's coworkers.) 


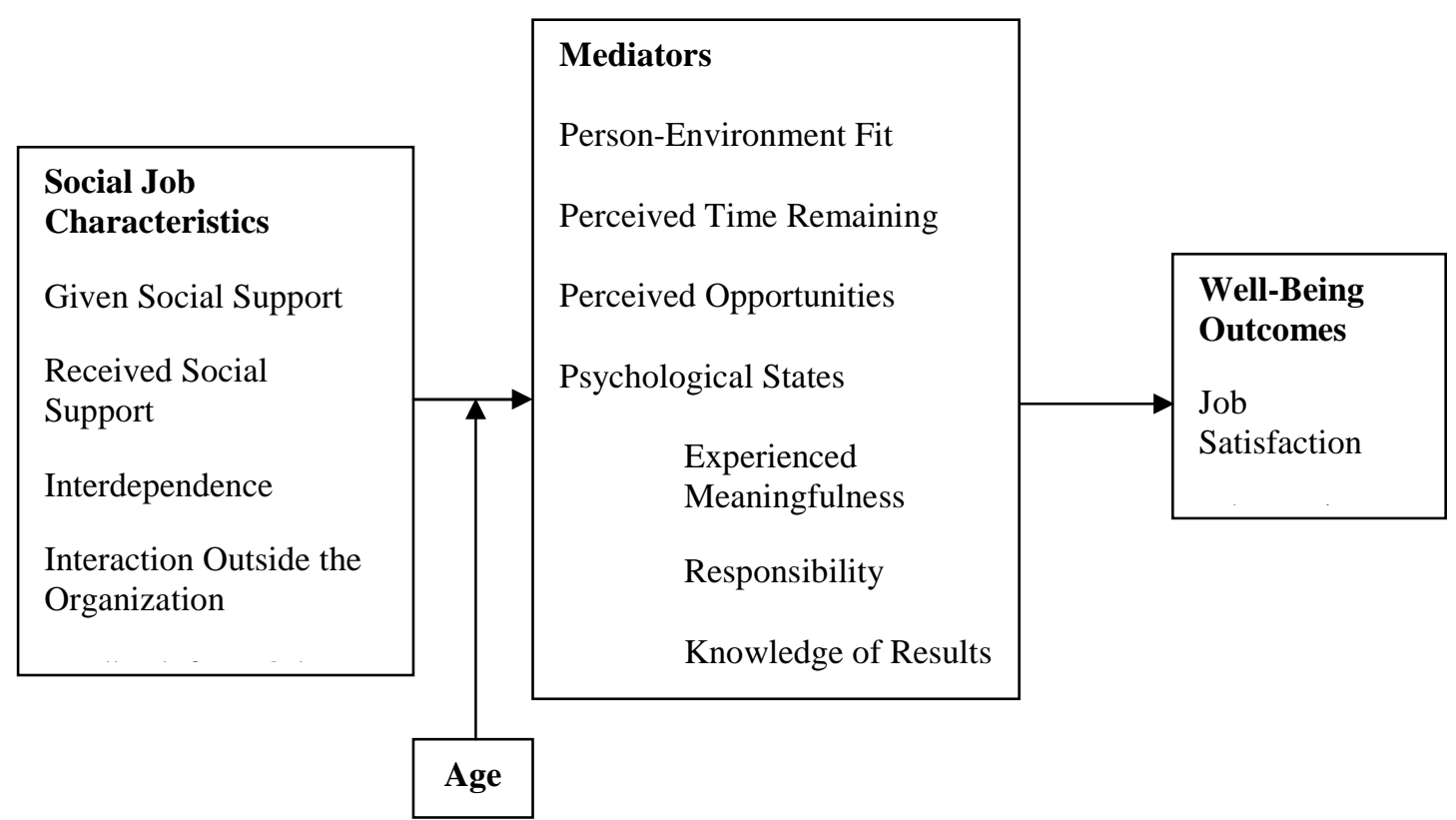

Figure 10. Proposed model for future research. 


\section{Appendix A}

\section{Questionnaire Measures}

\begin{tabular}{|l|l|c|c|c|c|c|}
\hline \multicolumn{2}{|l|}{ Given Social Support } & $\begin{array}{c}\text { Strongly } \\
\text { Disagree }\end{array}$ & Disagree & Neutral & Agree & $\begin{array}{c}\text { Strongly } \\
\text { Agree }\end{array}$ \\
\hline 1. & My job allows me to help my coworkers. & 1 & 2 & 3 & 4 & 5 \\
\hline 2. $\begin{array}{l}\text { My job allows me to take an interest in } \\
\text { coworkers. }\end{array}$ & 1 & 2 & 3 & 4 & 5 \\
\hline 3. $\begin{array}{l}\text { I have an opportunity to support others } \\
\text { at work. }\end{array}$ & 1 & 2 & 3 & 4 & 5 \\
\hline
\end{tabular}

\begin{tabular}{|l|l|c|c|c|c|c|}
\hline \multicolumn{2}{|l|}{} & $\begin{array}{l}\text { Strongly } \\
\text { Disagree }\end{array}$ & Disagree & Neutral & Agree & $\begin{array}{c}\text { Strongly } \\
\text { Agree }\end{array}$ \\
\hline 1. & $\begin{array}{l}\text { I have the opportunity to develop close } \\
\text { friendships in my job. }\end{array}$ & 1 & 2 & 3 & 4 & 5 \\
\hline 2. & $\begin{array}{l}\text { I have the chance in my job to get to } \\
\text { know other people. }\end{array}$ & 1 & 2 & 3 & 4 & 5 \\
\hline 3. & $\begin{array}{l}\text { I have the opportunity to meet with } \\
\text { others in my work. }\end{array}$ & 1 & 2 & 3 & 4 & 5 \\
\hline 4. & $\begin{array}{l}\text { My supervisor is concerned about the } \\
\text { wim/her. }\end{array}$ & 1 & 2 & 3 & 4 & 5 \\
\hline
\end{tabular}




\begin{tabular}{|c|c|c|c|c|c|c|}
\hline 5. & $\begin{array}{l}\text { People I work with take a personal } \\
\text { interest in me. }\end{array}$ & 1 & 2 & 3 & 4 & 5 \\
\hline 6. & People I work with are friendly. & 1 & 2 & 3 & 4 & 5 \\
\hline \multicolumn{7}{|c|}{ Interdependence } \\
\hline 7. & $\begin{array}{l}\text { The job requires me to accomplish my } \\
\text { job before others complete their job. }\end{array}$ & 1 & 2 & 3 & 4 & 5 \\
\hline 8. & Other jobs depend directly on my job. & 1 & 2 & 3 & 4 & 5 \\
\hline 9. & $\begin{array}{l}\text { Unless my job gets done, other jobs } \\
\text { cannot be completed. }\end{array}$ & 1 & 2 & 3 & 4 & 5 \\
\hline 10. & $\begin{array}{l}\text { My job activities are greatly affected by } \\
\text { the work of other people. }\end{array}$ & 1 & 2 & 3 & 4 & 5 \\
\hline 11. & $\begin{array}{l}\text { My job depends on the work of many } \\
\text { different people for its completion. }\end{array}$ & 1 & 2 & 3 & 4 & 5 \\
\hline 12. & $\begin{array}{l}\text { My job cannot be done unless others do } \\
\text { their work. }\end{array}$ & 1 & 2 & 3 & 4 & 5 \\
\hline \multicolumn{7}{|c|}{ Interaction Outside the Organization } \\
\hline 13. & $\begin{array}{l}\text { My job requires spending a great deal } \\
\text { of time with people outside my } \\
\text { organization. }\end{array}$ & 1 & 2 & 3 & 4 & 5 \\
\hline 14. & $\begin{array}{l}\text { My job involves interaction with people } \\
\text { who are not members of my } \\
\text { organization. }\end{array}$ & 1 & 2 & 3 & 4 & 5 \\
\hline 15. & $\begin{array}{l}\text { On the job, I frequently communicate } \\
\text { with people who do not work for the } \\
\text { same organization I do. }\end{array}$ & 1 & 2 & 3 & 4 & 5 \\
\hline
\end{tabular}




\begin{tabular}{|l|l|l|l|l|l|l|}
\hline 16. & $\begin{array}{l}\text { My job involves a great deal of } \\
\text { interaction with people outside my } \\
\text { organization. }\end{array}$ & 1 & 2 & 3 & 4 & 5 \\
\hline 17. & $\begin{array}{l}\text { from my manager and coworkers about } \\
\text { my job performance. }\end{array}$ & 1 & 2 & 3 & 4 & 5 \\
\hline 18. & $\begin{array}{l}\text { receive a great deal of information } \\
\text { information about the effectiveness } \\
\text { (e.g., quality and quantity) of my job } \\
\text { performance. }\end{array}$ & 1 & 2 & 3 & 4 & 5 \\
\hline 19. & $\begin{array}{l}\text { Other people in the organization, such } \\
\text { from other people in my organization } \\
\text { (such as my manager or coworkers). }\end{array}$ & 1 & 2 & 3 & 4 & 5 \\
\hline
\end{tabular}

\begin{tabular}{|c|c|c|c|c|c|}
\hline Comparative Age & $\begin{array}{l}\text { Much } \\
\text { Younger }\end{array}$ & Younger & $\begin{array}{l}\text { Neither } \\
\text { Older } \\
\text { nor } \\
\text { Younger }\end{array}$ & Older & $\begin{array}{l}\text { Much } \\
\text { Older }\end{array}$ \\
\hline \begin{tabular}{l|l} 
1. & In comparison to my coworkers, I would \\
describe myself as being
\end{tabular} & 1 & 2 & 3 & 4 & 5 \\
\hline
\end{tabular}

\begin{tabular}{|l|l|c|c|c|c|c|}
\hline \multicolumn{2}{|l|}{ Job Tension } & $\begin{array}{l}\text { Strongly } \\
\text { Disagree }\end{array}$ & Disagree & Neutral & Agree & $\begin{array}{c}\text { Strongly } \\
\text { Agree }\end{array}$ \\
\hline 1. & My job tends to directly affect my health. & 1 & 2 & 3 & 4 & 5 \\
\hline
\end{tabular}




\begin{tabular}{|c|l|c|c|c|c|c|}
\hline 2. & I work under a great deal of tension. & 1 & 2 & 3 & 4 & 5 \\
\hline 3. & $\begin{array}{l}\text { I have felt fidgety or nervous as a result } \\
\text { of my job. }\end{array}$ & 1 & 2 & 3 & 4 & 5 \\
\hline 4. & $\begin{array}{l}\text { If I had a different job, my health would } \\
\text { probably improve. }\end{array}$ & 1 & 2 & 3 & 4 & 5 \\
\hline 5. & $\begin{array}{l}\text { Problems associated with my job have } \\
\text { kept me awake at night. }\end{array}$ & 1 & 2 & 3 & 4 & 5 \\
\hline 6. & $\begin{array}{l}\text { I have felt nervous before attending } \\
\text { meetings in the company. }\end{array}$ & 1 & 2 & 3 & 4 & 5 \\
\hline 7. & $\begin{array}{l}\text { I often "take my job home with me" in } \\
\text { the sense that I think about it when } \\
\text { doing other things. }\end{array}$ & 1 & 2 & 3 & 4 & 5 \\
\hline
\end{tabular}

\begin{tabular}{|l|l|c|c|c|c|c|}
\hline \multicolumn{2}{|l|}{ Job Satisfaction } & $\begin{array}{l}\text { Strongly } \\
\text { Disagree }\end{array}$ & Disagree & Neutral & Agree & $\begin{array}{c}\text { Strongly } \\
\text { Agree }\end{array}$ \\
\hline 1. & l feel fairly satisfied with my present job. & 1 & 2 & 3 & 4 & 5 \\
\hline 2. & $\begin{array}{l}\text { Most days I am enthusiastic about my } \\
\text { monrk }\end{array}$ & 1 & 2 & 3 & 4 & 5 \\
\hline 3. & $\begin{array}{l}\text { Each day at work seems like it will never } \\
\text { end. }\end{array}$ & 1 & 2 & 3 & 4 & 5 \\
\hline 4. & l find real enjoyment in my work. & 1 & 2 & 3 & 4 & 5 \\
\hline 5. & I consider my job to be rather unpleasant. & 1 & 2 & 3 & 4 & 5 \\
\hline
\end{tabular}


Appendix $B$

\section{Survey Consent Letter}

You are invited to participate in a study conducted by Drs. Leslie Hammer and Donald Truxillo at Portland State University. They are studying the factors affecting employees' health, well-being, and work experiences. All workers at the Water Bureau's downtown office are invited to participate.

\section{How long will it take?}

If you decide to participate, we ask that you complete two questionnaires - this one, and a second survey we will send you in a few months. Each should take about 20 minutes. The surveys contain questions about your thoughts, feelings, and behaviors related to your job.

\section{As a participant, you:}

- Will have a chance to win one of six $\mathbf{\$ 5 0}$ Visa gift cards for each survey you complete

- Must complete this questionnaire by October 28th, 2011

\section{Are my responses confidential?}

- Your responses are completely confidential and will not be linked to you in any way

- We will match your survey now with the survey given in a few months by means of an anonymous code. We will also ask you to provide the name of your workgroup only so that we can analyze the data by workgroups.

- The results of this research will only be reported in aggregate form (everyone's information will be pooled together and summarized). No information on any individual or workgroup will be provided to management.

You do not have to take part in this study. Your participation will not affect your standing as an employee at the Water Bureau. You may also withdraw from this study at any time without affecting your relationship with the Water Bureau.

If you have concerns or questions about your rights as a participant, please contact:

Human Subjects Research Review Committee

Research + Strategic Partnerships (RSP)

PO Box 751, Portland, OR 97207

(503) 725-4288 / 1-877-480-4400 
If you have questions about the study itself, please contact:

Dr. Donald Truxillo

(503) 725-3969

truxillod@pdx.edu 


\section{References}

AARP, 2011. Best employers for workers over 50 - 2011 winners. AARP. Retrieved from http://aarp.org/work/on-the-job/info-09-2011/aarp-best-employers-winners2011.html

Aboa-Éboulé, C., Brisson, C., Maunsell, E., Mâsse, B., Bourbonnais, R., Vézina, M., Milot, A., Théroux, P., \& Dagenais, G.R. (2007). Job strain and risk of acute recurrent coronary heart disease events. Journal of the American Medical Association, 298, 1652-1660.

Adams, D. (1971). Correlates of satisfaction among the elderly. The Gerontologist, 6468.

Adams G. A., \& Beehr, T. A. (1998). Turnover and Retirement: A Comparison of Their Similarities and Differences. Personnel Psychology, 51, 643-665.

Ashford, S.J., \& Cummings, L.L. (1983). Feedback as an individual resource: Personal strategies of creating information. Organizational Behavior and Human Performance, 32, 370-389.

Baltes, P. B., \& Baltes, M. M. (1990). Psychological perspectives on successful aging: The model of selective optimization with compensation. In P. B. Baltes \& M. M. Baltes (Eds.), Successful aging: Perspectives from the behavioral sciences (pp. 134). New York: Cambridge University Press. 
Baltes, P. B. \& Dickson, M.W. (2001). Using life-span models in industrialorganizational psychology: The theory of selective optimization with compensation. Applied Developmental Science, 5, 51-62.

Baltes, P. B., Staudinger, U. M., \& Lindenberger, U. (1999). Lifespan psychology: Theory and application to intellectual functioning. Annual Review of Psychology, 50, 471-507.

Barak, B. (1987). Cognitive Age: A new multidimensional approach to measuring age identity. The International Journal of Aging and Human Development, 25, 109127.

Barak, B. \& Gould, S. (1985). Alternative age measures: A research agenda. In E.C. Hirshman \& M.B. Holbrook (Eds.), Advances in consumer research, 12, 53-58.

Barak, B., \& Stern, B. (1986). Subjective age correlates: A research note. The Gerontologist, 26, 571-578.

Barling, J., \& Griffiths, A. (2011). A history of occupational health psychology. In J.C. Quick \& L. E. Tetrick (Eds.), Handbook of Occupational Health Psychology, $2^{\text {nd }}$ Edition (pp. 21-34). Washington, D.C.: American Psychological Association.

Barnes-Farrell, J. L., \& Piotrowski, M. J. (1991). Discrepancies between chronological age and personal age as a reflection of unrelieved worker stress. Work \& Stress, 5, $177-187$. 
Barnes-Farrell, J. L., Rumery, S.M., \& Swody, C.A. (2002). How Do Concepts of Age Relate to Work and Off-the-Job Stresses and Strains? A Field Study of Health Care Workers in Five Nations. Experimental Aging Research, 28, 87-98.

Belschak, F. N., \& Den Hartog, D.N. (2009). Consequences of positive and negative feedback: The impact on emotions and extra-role behaviors. Applied Psychology: An International Review, 58, 274-303.

Birren, J., \& Cunningham, W. (1985). Research on the psychology of aging: principles, concepts, and theory. In Handbook of Aging and Psychology, JE Birren \& K Schaie (Eds.), (pp.3-34). New York: Van Nostrand Reinhold.

Brayfield, A.H., \& Rothe, H.F. (1951). An index of job satisfaction. Journal of Applied Psychology, 35, 307-311.

Brief, A.P., \& Weiss, H.M. (2002). Organizational behavior: Affect in the workplace. Annual Review of Psychology, 53, 279-307.

Cadiz, D. M. (2009). Subjective age in the workplace: Exploring the nomological network. Unpublished master's thesis, Portland State University, Portland, OR, USA.

Cadiz, D. M. (2011). The effects of ageism climates and core self-evaluations on nurses' turnover intentions, organizational commitment, and work engagement. Unpublished doctoral dissertation, Portland State University, Portland, OR, USA.

Carone, G., \& Costello, D. (2006). Can Europe afford to grow old? Finance and Development, 43, 1-9. 
Carstensen, L. L. (2006). The influence of a sense of time on human development. Science, 312, 1913-1915.

Carstensen, L. L. (1991). Socioemotional selectivity theory: Social activity in life-span context. Annual Review of Gerontology and Geriatrics. 17, 195-217.

Carstensen, L.L., Isaacowitz, D.M., \& Charles, S.T. (1999). Taking time seriously: A theory of socioemotional selectivity. American Psychologist, 54, 165-181.

Cleveland, J.N. \& Shore, L.M. (1992). Self- and supervisory perspectives on age and work attitudes and performance. Journal of Applied Psychology, 77, 469-484.

Cohen, S. \& Wills, T.A. (1985). Stress, social support, and the buffering hypothesis. Psychological Bulletin, 98, 310-357.

Cropanzano, R., Howes, J.C., Grandey, A., \& Toth, P. (1997). The relationship of organizational politics and support to work behaviors, attitudes, and stress. Journal of Organizational Behavior, 18, 159-180.

Dannefer, D. (1987). Aging as intracohort differentiation, the Matthew effect, and the life course. Sociological Forum, 2, 211-236.

De Lange, A.H., Taris, T.W., Kompier, M., Houtman, I.L., \& Bongers, P.M. (2003). "The very best of the millennium": Longitudinal research and the demandcontrol-(support) model. Journal of Occupational Health Psychology, 8, 282-305.

Demerouti, E., Bakker, A.B., Nachreiner, F., \& Schaufeli, W.B. (2001). The job demands-resources model of burnout. Journal of Applied Psychology, 86, 499512. 
Diefendorff, J.M., Richard, E.M. \& Croyle, M.H. (2006). Are emotional display rules formal job requirements? Examination of employee and supervisor perceptions. Journal of Occupational and Organizational Psychology, 79, 273-298.

Diener, E., \& Suh, M. E. (1997). Subjective well-being and age: An international analysis. Annual Review of Gerontology and Geriatrics, 17, 304-324.

Dunnette, M.D., Campbell, J.P., \& Hakel, M.D. (1967). Factors contributing to job satisfaction and job dissatisfaction in six occupational groups. Organizational Behavior and Human Performance, 2, 143-174.

Dwyer, D.J. \& Ganster, D.C. (1991). The effects of job demands and control on employee attendance and satisfaction. Journal of Organizational Behavior, 12, 595-608.

Ebner, N. C., Freund, A. M., \& Baltes, P. B. (2006). Developmental changes in personal goal orientation from young to late adulthood : From striving for gains to maintenance and prevention of losses. Psychology and Aging, 21, 664-678.

Faul, F., Erdfelder, E., Buchner, A., \& Lang, A.-G. (2009). Statistical power analyses using $\mathrm{G}^{*}$ Power 3.1: Tests for correlation and regression analyses. Behavior Research Methods, 41, 1149-1160.

Feldman, D. C., \& Beehr, T. A. (2011, February 21). A three-phase model of retirement decision making. American Psychologist. Advance online publication. 
Fried, Y., Grant, A.M., Levi, A.S., Hadani, M., \& Haynes Slowik, L. (2007). Job design in temporal context: A career dynamics perspective. Journal of Organizational Behavior, 28, 911-927.

Freund, A.M. (2006). Age-differential motivational consequences of optimization versus compensation focus in younger and older adults. Psychology and Aging, 21, 240252.

Ford, M.T., Heinen, B.A. \& Langkamer, K.L. (2007). Work and family satisfaction and conflict: A meta-analysis of cross-domain relations. Journal of Applied Psychology, 92, 57-80.

Grandey, A.A. (2000). Emotion regulation in the workplace: A new way to conceptualize emotional labor. Journal of Occupational Health Psychology, 5, 95-110.

Grant, A.M. (2008). The significance of task significance: Job performance effects, relational mechanisms, and boundary conditions. Journal of Applied Psychology, 93, 108-124.

Grant, A. M., Fried, Y., \& Juillerat, T. (2010). Work matters: Job design in classic and contemporary perspectives. In S. Zedeck (Ed.), APA Handbook of Industrial and Organizational Psychology, 1 (pp. 417-453). Washington, DC: American Psychological Association.

Gully, S. M., Incalcaterra, K. A., Joshi, A., \& Beaubien, J. M. (2002). A meta-analysis of team-efficacy, potency, and performance: Interdependence and level of analysis 
as moderators of observed relationships. Journal of Applied Psychology, 87, 819832.

Hackman, J. R., \& Oldham, G. R. (1975). Development of the Job Diagnostic Survey. Journal of Applied Psychology, 60, 159-170.

Herzberg, F. (1966). Work and the nature of man. Cleveland, OH: World.

Hochschild, A.R. (1983). The managed heart: Commercialization of human feeling. Berkeley: University of California Press.

House, R.J. \& Rizzo, J.R. (1972). Toward the measurement of organizational practices: Scale development and validation. Journal of Applied Psychology, 56, 388-396.

House, J. S., Landis, K. R. \& Umberson, D. (1988). Social relationships and health. Science, 241, 540-545.

Humphrey, S. E., Nahrgang, J. D., \& Morgeson, F. P. (2007). Integrating motivational, social, and contextual work design features: A meta-analytic summary and theoretical extension of the work design literature. Journal of Applied Psychology, 92, 1332-1356.

Hunthausen, J.M., Truxillo, D.M., Bauer, T.N., \& Hammer, L.B. (2003). A field study of frame-of-reference effects on personality test validity. Journal of Applied Psychology, 88, 545-551. 
Jackson, S.E. (1982). After-effects of job-related stress: Families as victims. Journal of Organizational Behavior, 3, 63-77.

Jansen, K. J., \& Kristof-Brown, A. ( 2006 ). Toward a multidimensional theory of person environment fit . Journal of Managerial Issues , 18, 193 - 212.

Judge, T. A., Bono, J. E. \& Locke, E. A. (2000). Personality and Job Satisfaction: The Mediating Role of Job Characteristics. Journal of Applied Psychology, 85, 237249.

Kacmar, K.M. (1999). An examination of the perceptions of organizational politics model: Replication and extension. Human Relations, 52, 383-417.

Kanfer, R. \& Ackerman, P.L. (2004). Aging, work motivation, and adult development. Academy of Management Review, 29, 440-458.

Karasek, R.A. (1979). Job demands, job decision latitude, and mental strain: Implications for job redesign. Administrative Science Quarterly, 24, 285-308.

Karasek, R. Brisson, C. Kawakami, N. Houtman, I. Bongers, P. \& Amick, B. (1998). The Job Content Questionnaire (JCQ): An instrument for internationally comparative assessments of psychosocial job characteristics. Journal of Occupational Health Psychology, 3, 322-355.

Karasek, R. A., \& Theorell, T. (1990). Healthy work: Stress, productivity, and the reconstruction of working life. New York: Basic Books. 
Kastenbaum, R., Derbin, V., Sabatini, P., \& Artt, S. (1972). "The ages of me”: Toward personal and interpersonal definitions of functional aging. The International Journal of Aging and Human Development, 3, 197-211.

Kiggundu, M. N. (1983). Task interdependence and job design: Test of a theory. Organizational Behavior and Human Performance, 31, 145-172.

Kooij, D. T. A., de Lange, A. H., Jansen, P. G. W., Kanfer, R., \& Dikkers, J. S. E. (2011). Age and work-related motives: The results of a meta-analysis. Journal of Organizational Behavior, 32, 197-225.

Kristof-Brown , A. L. , Zimmerman , R. D. , \& Johnson , E. C . ( 2005 ). Consequences of individual's fit at work: A meta-analysis of person-job, person-organization, person-group, and person-supervisor fit . Personnel Psychology, 58, $281-342$.

LeBlanc, P., de Jonge, J. \& Schaufeli, W. (2000). Job stress and health. In N. Chmiel (Ed.), Work and Organizational Psychology: A European Perspective (pp. 148178). Oxford, UK: Wiley-Blackwell.

LePine, J.A., LePine, M.A., \& Jackson, C.L. (2004). Challenge and hindrance stress: Relationships with exhaustion, motivation to learn, and learning performance. Journal of Applied Psychology, 89, 883-891.

Levy, P.E., Albright, M.D., Cawley, B.D., \& Williams, J.R. (1995). Situational and individual determinants of feedback seeking: A closer look at the process. Organizational Behavior and Human Decision Processes, 
Malinen, S. (2009). Implicit and Explicit Attitudes towards Older Workers: Their Predictive Utility and the Role of Attitude Malleability. (Unpublished doctoral dissertation). University of Canterbury, Christchurch, New Zealand.

Morgeson, F. P., \& Campion, M. A. (2003). Work design. In W. C. Borman, D. R. Ilgen, \& R. J. Klimoski (Eds.), Handbook of Psychology: Industrial and Organizational Psychology (Vol. 12, pp. 423-452). Hoboken, NJ: John Wiley \& Sons.

Morgeson, F.P. \& Humphrey S.E. (2006). The Work Design Questionnaire (WDQ):

Developing and validating a comprehensive measure for assessing job design and the nature of work. Journal of Applied Psychology, 91, 1321-1399.

Morgeson, F. P., \& Humphrey, S. E. (2008). Job and team design: Toward a more integrative conceptualization of work design. In J. Martocchio (Ed.), Research in Personnel and Human Resource Management (Vol. 27, pp. 39-92). United Kingdom: Emerald Group Publishing Limited.

Ng, T. \& Feldman, D.C. (2008). The relationship of age to ten dimensions of job performance. Journal of Applied Psychology, 93, 392-423.

Ng, T. \& Feldman, D. C. (2010). The relationships of age with job attitudes: A metaanalysis. Personnel Psychology, 63, 677-718.

Organ, D.W. \& Ryan, K. (1995). A meta-analytic review of attitudinal and dispositional predictors of organizational citizenship behavior. Personnel Psychology, 48, 775802. 
Parker, S. \& Wall, T (1998). Job and Work Design: Organizing Work to Promote Wellbeing and Effectiveness. San Francisco, CA: Sage.

Perry, E. L., Dokko, G., \& Golom, F. (2012). The aging worker and person-environment fit. In J. W. Hedge \& W. C. Borman (Eds.), The Oxford Handbook of Work and Aging. Oxford, UK: Oxford University Press.

Roberts, B. W., Wood, K. E., \& Viechtbauer, W. (2006). Patterns of mean-level change in personality traits across the life course: A meta-analysis of longitudinal studies. Psychological Bulletin, 132, 1-25.

Robins, R. W., Trzesniewski, K. H., Tracy, J. L., Gosling, S. D., \& Potter, J. (2002). Global self-esteem across the life span. Psychology and Aging, 17, 423-434.

Rodell, J.B., \& Judge, T.A. (2009). Can "good" stressors spark "bad" behaviors? The mediating role of emotions in links of challenge and hindrance stressors with citizenship and counterproductive behaviors. Journal of Applied Psychology, 94, $1438-1451$.

Saavedra, R. Earley, P.C., \& Van Dyne, L. (1993). Complex interdependence in taskperforming groups. Journal of Applied Psychology, 78, 61-72.

Sanchez, J.I., \& Brock, P. (1996). Outcomes of perceived discrimination among Hispanic employees: Is diversity management a luxury or a necessity? Academy of Management Journal, 39, 704-719. 
Sauter, S., Murphy, L., Colligan, M., Swanson, N., Hurrell, J., Scharf, F., Sinclair, R., Grubb, P., Goldenhar, L., Alteman, T., Johnston, J., Hamilton, A., \& Tisdale, J. (1999). Stress... At Work (DHHS [NIOSH] Publication Number 99-101).

Cincinnati, OH: National Institute for Occupational Safety and Health.

Settersten, R. \& Mayer, K. (1997). The Measurement of Age, Age Structuring, and the Life Course. Annual Review of Sociology, 23, 233-261.

Sullivan, S.J., Mikels, J.A., \& Carstensen, L.L. (2010). You never lose the ages you've been: Affective perspective taking in older adults. Psychology and Aging, 25, 229-234.

Tabachnick, B. G., \& Fidell, L. S. (2007). Using Multivariate Statistics. Boston: Pearson. Taylor, F.W. (1911). The principles of scientific management. New York, NY: Harper. Tossi, M. (2009). Labor force projections to 2018 : Older workers staying more active. Monthly Labor Review, 132, 30-51.

Trist, E.L. (1981). The evolution of socio-technical systems: A conceptual framework and an action research program. Occasional Paper Number 2, 1-67.

Trist, E.L. \& Bamforth, K.W. (1951). Some social and psychological consequences of the longwall method of coal-getting. Human Relations, 4, 3-38.

Truxillo, D. M., Cadiz, D. A., \& Rineer, J. R. (2012). Designing jobs for an aging workforce: An opportunity for occupational health. In J. Houdmont, S. Leka, \& R. R. Sinclair (Eds.), Contemporary Occupational Health Psychology: Global 
Perspectives on Research and Practice, Volume 2, pp. 109-125. Chichester, UK: Wiley-Blackwell.

Truxillo, D., Cadiz, D., Rineer, J., Zaniboni, S., \& Fraccaroli, F. (under review). A lifespan perspective on job design: Fitting the worker to the job to promote job satisfaction. Organizational Psychology Review.

Tsui, A. S., Egan, T. D., \& O'Reilly, C. A. (1992). Being different: Relational demography and organizational attachment. Administrative Science Quarterly, 37, $547-579$.

Van Den Broek, A., De Cuyper, N., De Witte, H. \& Vansteenkiste, M. (2010). Not all job demands are equal: differentiating job hindrances and job challenges in the Job

Demands- $\quad$ Resources Model. European Journal of Work and Organizational Psychology, 19, 735-759.

Wilson, M. G., Dejoy, D. M., Vandenberg, R. J., Richardson, H. A., \& McGrath, A. L. (2004). Work characteristics and employee health and well-being: Test of a model of healthy work organization. Journal of Occupational \& Organizational Psychology, 77, 565-588.

Wrzesniewski, A., \& Dutton, J. E. (2001). Crafting a job: Revisioning employees as active crafters of their work. Academy of Management Review, 26, 179-201. 
Zacher, H., \& Frese, M. (2009). Remaining time and opportunities at work: Relationships between age, work characteristics, and occupational future time perspective. Psychology and Aging, 24, 487-493.

Zacher, H., Heusner, S., Schmitz, M., Zwierzanska, M. and Frese, M. (2010). Focus on opportunities as a mediator of the relationships between age, job complexity, and work performance. Journal of Vocational Behavior, 76, 374-386.

Zaniboni, S., Truxillo, D. M., Fraccaroli, F., McCune, E. A., \& Bertolino, M. (2011). Age moderates the effects of WDQ factors on job attitudes. In K. James and G. Burlacu (Chairs), Age and Career Development in a Changing World of Work. Paper presented at the 2011 SIOP Conference, Chicago, IL.

Zivnuska, S., Kiewitz, C., Hochwater, W. A., Perrewe, P. L., \& Zellars, K. L. (2002). What is too much or too little? The curvilinear effects of job tension on turnover intent, value attainment, and job satisfaction. Journal of Applied Social Psychology, 32, 1344-13. 